\title{
Pseudo steady states of HONO measured in the nocturnal marine boundary layer: a conceptual model for HONO formation on aqueous surfaces
}

\author{
P. Wojtal, J. D. Halla, and R. McLaren \\ Centre for Atmospheric Chemistry, York University, Toronto, ON, Canada \\ Received: 7 September 2010 - Published in Atmos. Chem. Phys. Discuss.: 27 October 2010 \\ Revised: 3 March 2011 - Accepted: 30 March 2011 - Published: 5 April 2011
}

\begin{abstract}
A complete understanding of the formation mechanism of nitrous acid (HONO) in the ambient atmosphere is complicated by a lack of understanding of processes occurring when aqueous water is present. We report nocturnal measurements of $\mathrm{HONO}, \mathrm{SO}_{2}$ and $\mathrm{NO}_{2}$ by differential optical absorption spectroscopy over the ocean surface in a polluted marine environment. In this aqueous environment, we observed reproducible pseudo steady states (PSS) of HONO every night, that are fully formed shortly after sunset, much faster than seen in urban environments. During the PSS period, HONO is constant with time, independent of air mass source and independent of the concentration of $\mathrm{NO}_{2}$. The independence of $\mathrm{HONO}$ on the concentration of $\mathrm{NO}_{2} \mathrm{im}$ plies a $0^{\circ}$ order formation process, likely on a saturated surface, with reversible partitioning of HONO to the gas phase, through vaporization and deposition to the surface. We observed median $\mathrm{HONO} / \mathrm{NO}_{2}$ ratios starting at 0.13 at the beginning of the PSS period (with an apparent lower bound of 0.03 ), rising to median levels of $\sim 0.30$ at the end of the PSS period (with an upper bound $>1.0$ ). The implication of these numbers is that they suggest a common surface mechanism of HONO formation on terrestrial and aqueous surfaces, with an increase in the $\mathrm{HONO} / \mathrm{NO}_{2}$ ratio with the amount of water available at the surface. The levels of HONO during the nocturnal PSS period are positively correlated with temperature, consistent with a partitioning of HONO from the surface to the gas phase with an apparent enthalpy of vaporization of $\Delta H_{\mathrm{SNL}}(\mathrm{HONO})=55.5 \pm 5.4 \mathrm{~kJ} \mathrm{~mol}^{-1}$. The formation mechanism on aqueous surfaces is independent of relative humidity $(\mathrm{RH})$, despite observation of a negative HONO-RH corre-
\end{abstract}

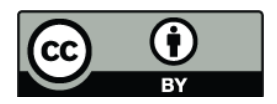

Correspondence to: R. McLaren (rmclaren@yorku.ca) lation. A conceptual model for HONO formation on ambient aqueous surfaces is presented, with the main elements being the presence of a surface nanolayer (SNL), highly acidic and saturated with $\mathrm{N}(\mathrm{IV})$ precursors, production of $\mathrm{HNO}_{3}$, that diffuses to underlying water layers, and HONO, which partitions reversibly between the SNL and the gas phase. Implications of the conceptual model are discussed.

\section{Introduction}

The importance of nitrous acid (HONO) in the polluted atmosphere has been known for some time (Harris et al., 1982). Highest concentrations of HONO are typically seen in the boundary layer at night (Kitto and Harrison, 1992) due to significant loss of HONO by photolysis during the day. Photolysis of HONO is often the major source of $\mathrm{OH}$ in the morning boundary layer (Platt et al., 1980), and has been estimated to contribute from $17-34 \%$ of the total $\mathrm{OH}$ production integrated over $24 \mathrm{~h}$ in polluted environments (Alicke et al., 2002, 2003). While HONO typically declines during the day due to significant photolytic losses, the residual levels that exist at mid day suggest that a significant daytime source of HONO must also exist (Zhou et al., 2002; Kleffmann et al., 2003). Photolysis of surface adsorbed nitric acid (Zhou et al., 2002) and photoenhanced uptake of $\mathrm{NO}_{2}$ on organic surfaces have been suggested as potential daytime photolytic sources of HONO (George et al., 2005). Despite significant research activity and its importance, a complete understanding of the atmospheric sources and sinks of HONO during both daytime and nightime has remained elusive. Some consensus has been achieved though. It is generally believed that in urban areas a direct fuel combustion source of HONO exists with a $\mathrm{HONO} / \mathrm{NO}_{\mathrm{x}}$ ratio typically below 0.01 (Kurtenbach et al.,

Published by Copernicus Publications on behalf of the European Geosciences Union. 
2001). HONO can also be formed in small amounts through heterogeneous reaction of $\mathrm{NO}_{2}$ on fresh soot aerosol surfaces (Aubin and Abbatt, 2007), an observation that is likely not independent from the fuel combustion source. More importantly, observations in the nocturnal boundary layer indicate a significant surface source of HONO (Harrison and Kitto, 1994), as indicated by negative gradients of HONO and positive gradients of $\mathrm{NO}_{2}$ with respect to height above ground (Harrison et al., 1996; Stutz et al., 2002; Wang et al., 2006). The ground usually presents a higher surface area in the nocturnal boundary layer compared to the surface area of aerosols for $\mathrm{NO}_{2}$ conversion (Yu et al., 2009; Stutz et al., 2004); the aerosol surface area gains relative importance with increasing height of the mixed layer (Lammel, 1999). There is also significant laboratory based evidence for a surface source of HONO originating from the heterogeneous reaction of $\mathrm{NO}_{2}$ on a range of laboratory surfaces including glass, quartz, steel and even teflon (Lammel, 1999; Finlayson-Pitts et al., 2003 and references therein). The conversion of $\mathrm{NO}_{2}$ to $\mathrm{HONO}$ on surfaces is generally believed to proceed with the following stoichiometry,

$\mathrm{NO}_{2}+\mathrm{NO}_{2}+\mathrm{H}_{2} \mathrm{O} \rightarrow \mathrm{HONO}+\mathrm{HNO}_{3}$,

with minor products $\mathrm{NO}$ and $\mathrm{N}_{2} \mathrm{O}$ observed in laboratory studies, with high $\mathrm{NO}_{2}$ levels, highly acidic surfaces and high surface to volume $(S / V)$ ratios (Finlayson-Pitts et al., 2003).

Despite the stoichiometry of Reaction (R1), the rate of the surface reaction on these laboratory surfaces is generally believed to be first order in $\mathrm{NO}_{2}$ (Jenkin et al., 1988) and was thought originally to be first order in water vapor as well. Recent reviews suggest that the dependence on water vapor is complicated, since the reaction is thought not to proceed in the gas phase. More correctly, relative humidity can be described as a surrogate for the amount of water adsorbed chemically or physically onto the surface where the heterogeneous reaction proceeds (Lammel and Cape, 1996; Finlayson-Pitts et al., 2003; Stutz et al., 2004).

The normalized $\mathrm{HONO} / \mathrm{NO}_{2}$ ratio and/or production rates in ambient air are often used as an indicator of the extent of $\mathrm{NO}_{2}$ conversion to $\mathrm{HONO}$, with an implicit assumption that the heterogeneous formation mechanism is first order in $\mathrm{NO}_{2}$ on all surface types. Ambient measurements suggest that $\mathrm{HONO} / \mathrm{NO}_{2}$ ratios of less than 0.01 are associated with direct fuel combustion sources (Kurtenbach et al., 2001), ratios up to 0.03 are associated with surface sources in low relative humidity environments while ratios of up to 0.10 are associated with high relative humidity (Stutz et al., 2004). A pseudo steady state (PSS) can often be achieved at night (Harrison and Kitto, 1994) that has been suggested to be a balance between the heterogeneous $\mathrm{NO}_{2}$ to $\mathrm{HONO}$ conversion on the surface and simultaneous deposition of HONO on the surface (Stutz et al., 2004). Several studies mention the unusual temporal profile of constant HONO or a "levelling off" of HONO throughout the night (Lammel and Cape,
1996; Stutz et al., 2004, 2002; Yu et al., 2009), consistent with the existence of a PSS.

A compilation of HONO measurements in urban and rural areas showed that while higher nighttime levels of HONO are generally seen in the urban area, the source strength when normalized to $\mathrm{NO}_{2}$ is similar in both areas, spanning a $\mathrm{HONO} / \mathrm{NO}_{2}$ range of $1.7-13 \%$ determined at the time of maximum HONO (Lammel and Cape, 1996). More recently, $\mathrm{HONO} / \mathrm{NO}_{2}$ ratios up to $30 \%$ have been reported (Yu et al., 2009) in the nocturnal atmosphere of Kathmandu, Nepal where a combination of low inversion layer, high pollution and high relative humidity are invoked to explain the efficient conversion of $\mathrm{NO}_{2}$ to $\mathrm{HONO}$.

Despite the importance of surface water in the $\mathrm{HONO} / \mathrm{NO}_{2}$ conversion, the role of the air/water interface in bulk water systems as a potential surface source for the heterogeneous reaction remains uncertain (Lammel, 1999). There is evidence that HONO can be formed heterogeneously on the surface of cloud water droplets (Acker et al., 2000). Using a liquid droplet train (Ponche et al., 1993) and liquid jet techniques (Mertes and Wahner, 1995), two studies found much higher rates of uptake of $\mathrm{NO}_{2}$ on the aqueous surface, faster than could be accounted for by bulk-phase solubility and homogeneous reaction in solution, the latter study also showing partial release of HONO to the gas phase. In contrast, a subsequent study (Cheung et al., 2000) found no evidence for an aqueous surface reaction of $\mathrm{NO}_{2}$ using droplet train and bubble train flow reactors; instead invoking the bulk-phase solubility and reaction for disappearance of $\mathrm{NO}_{2}$. In a comprehensive review of all evidence of $\mathrm{NO}_{2}$-HONO conversion in laboratory systems and outdoor atmospheres, Finlayson-Pitts et al. (2003) proposed a detailed integrated mechanism for HONO production via Reaction (R1) that involves the reaction of $\mathrm{NO}_{2}$ (or its derivatives) on any surface, where the chemical nature of the surface is not important other than its ability to act as a physical support for thin films of surface water. The suggested mechanism involves the uptake or formation of the symmetric $\mathrm{NO}_{2}$ dimer on the surface, $\mathrm{N}_{2} \mathrm{O}_{4}$, isomerization to the asymmetric form $\mathrm{ONONO}_{2}$, autoionization to $\mathrm{NO}^{+} \mathrm{NO}_{3}^{-}$, and reaction with water to generate surface adsorbed $\mathrm{HNO}_{3}$ and gaseous HONO. It was shown therein, that the $\mathrm{NO}_{2}$ to $\mathrm{HONO}$ conversion in these systems could not be accounted for by bulk aqueous phase kinetics, although the question of the reaction occurring on the surface of a bulk water system was not addressed directly.

Summaries of HONO observations (Kitto and Harrison, 1992; Lammel and Cape, 1996; Yu et al., 2009) indicate that measurements have been made in a wide range of locations including urban, suburban, rural, remote and arctic atmospheres. However, reports of HONO measurements in the marine boundary layer (MBL) are almost nonexistent, with but one brief mention of HONO measured in the open Agean Sea (Večeřa et al., 2008). The absence of HONO 
measurements in "aqueous" environments (Lammel, 1999), the limited study of the water dependence of HONO formation in the real atmosphere (Stutz et al., 2004), and the levels of HONO that may exist in polluted marine environments (Osthoff et al., 2008) have all been questioned recently. The presence of HONO in the polluted MBL may be important since $\mathrm{HONO}$ and chlorine containing photolabile species, $\mathrm{ClNO}_{2}, \mathrm{ClNO}, \mathrm{Cl}_{2}$, may compete as the main radical sources in these environments in early morning, yielding $\mathrm{OH}$ and $\mathrm{Cl}$, respectively. There was early evidence that HONO is produced in the reaction of $\mathrm{N}_{2} \mathrm{O}_{5}$ with wet $\mathrm{NaCl}$ aerosols (Junkermann and Ibusuki, 1992). Production of $\mathrm{ClNO}_{2}$ from reaction of $\mathrm{N}_{2} \mathrm{O}_{5}$ with $\mathrm{NaCl}$ has been observed in laboratory experiments (Finlayson-Pitts et al., 1989) and the first observations of ambient $\mathrm{ClNO}_{2}$, highly correlated with $\mathrm{N}_{2} \mathrm{O}_{5}$ were recently reported in the MBL (Osthoff et al., 2008). Still more recently, evidence was presented to show that $\mathrm{ClNO}_{2}$ is an intermediate in the production of $\mathrm{Cl}_{2}$ from the reaction of $\mathrm{N}_{2} \mathrm{O}_{5}$ with $\mathrm{Cl}^{-}$in acidic aerosols, and a hypothesized mechanism therein indicates that HONO may be produced in the reaction (Roberts et al., 2008). Thus despite a lack of measurements, HONO formation in the polluted MBL is clearly of strong interest.

In this work, we report measurements of $\mathrm{HONO}, \mathrm{SO}_{2}$, and $\mathrm{NO}_{2}$ by active differential optical absorption spectroscopy (DOAS) in the MBL south of Vancouver, British Columbia, in a polluted region impacted by surrounding coastal cities and marine vessel emissions. This work continues data analysis of a spectral database from which $\mathrm{NO}_{3}$ levels in the polluted marine boundary layer were reported (McLaren et al., 2010), establishing a link between nighttime chemistry in the MBL layer and ozone formation in the adjacent populated coastal region. With respect to potential HONO formation mechanisms, the marine boundary layer represents a unique, yet interesting environment due to the apparent simplicity of the surfaces available for HONO formation compared to terrestrial environments. The only surfaces of significance to act as source/sink of HONO are the air sea-surface interface and the surface of MBL aerosols, including deliquesced sea salt and anthropogenic aerosols. The highly aqueous surfaces in this environment are expected to be unchanging with time to a first approximation, and independent of relative humidity, compared to terrestrial urban atmospheres. We report analysis of HONO measurements for 12 nights in the MBL. The PSS that develops each night in the MBL has important implications for HONO formation mechanisms.

\section{Experimental}

\subsection{Location and instrumentation}

The location of the measurement site is shown in Fig. 1 and has been described in more detail previously (McLaren et al., 2010). Briefly, instrumentation was located at the eastern tip

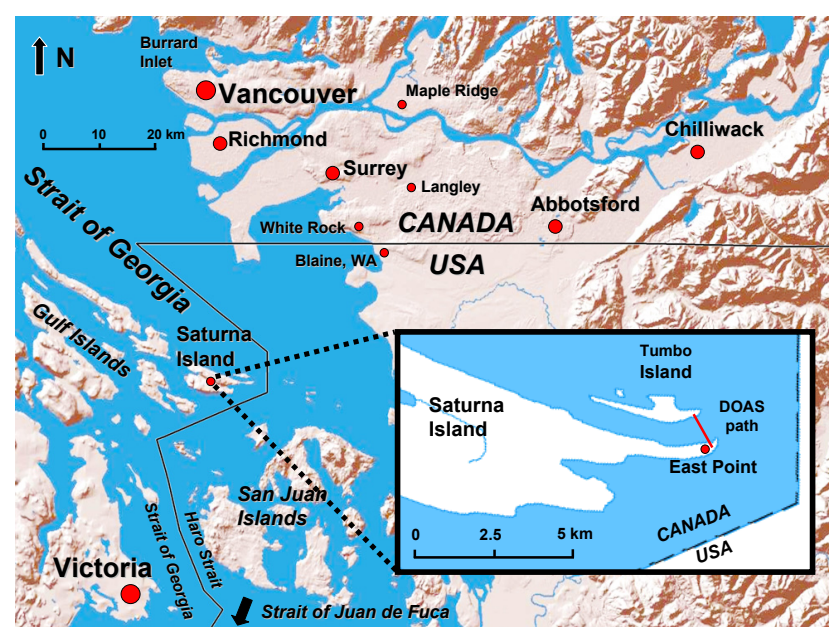

Fig. 1. Study location.

of Saturna Island (East Point) in the Strait of Georgia. The surrounding marine area is polluted by a variety of sources including major populated cities in British Columbia (Vancouver and Victoria) and Washington State (Bellingham and Seattle), as well as emissions from marine vessels arriving and departing from large ports in the major cities. Saturna Island itself has a low population density, especially at its eastern fringes, and has very few anthropogenic emissions that would influence the measurements. The DOAS instrumentation described in detail previously (McLaren et al., 2010) was located on a grassy patch next to the ocean at an elevation of $23 \mathrm{~m}$ a.s.l. Meteorological observations were taken at a height of $24.4 \mathrm{~m}$ a.s.l. within a few meters of the DOAS telescope (Environment Canada, 2008). The DOAS retro reflector was located on Tumbo Island (Fig. 1) at an elevation of $6 \mathrm{~m}$ a.s.l. and distance of $1203.5 \mathrm{~m}$ for a return path length of $2.41 \mathrm{~km}$, with $2.16 \mathrm{~km}$ of the path over the open ocean at a mean elevation of $15 \mathrm{~m}$ a.s.l. The return beam was focused onto a bifurcated quartz fiber optic (Ocean Optics) with two $400 \mu \mathrm{m}$ fibers, each leading to a different fiber optic spectrometer. One spectrometer was optimized for the UV spectral region (USB2000, Grating \#10, 295-492 nm, 1800 lines $\mathrm{mm}^{-1}$, 2048 element CCD, $25 \mu \mathrm{m}$ slit, UV2 upgrade, L2 lens, optical resolution of $\sim 0.5 \mathrm{~nm}$ ), and was used for measurement of $\mathrm{HONO}, \mathrm{NO}_{2}$ and $\mathrm{SO}_{2}$. The other spectrometer was optimized for measurement of $\mathrm{NO}_{3}$ and will not be discussed here. A small diffuser was placed in the entrance of the fiber to lower atmospheric turbulence noise (Stutz and Platt, 1997). The spectrometers were cooled to $-5^{\circ} \mathrm{C}$ in a portable freezer.

Custom acquisition software was written in LabView to acquire spectra from the spectrometer with typical integration times of $200-300 \mathrm{~ms}$, and 2500 averages for spectra with a time resolution of 8-12 min. Mercury lamp reference spectra were collected periodically for wavelength calibration and for convoluting molecular reference spectra to the 
slit function of the spectrometer. Xenon lamp, electronic offset and dark noise spectra were collected periodically for use in fitting routines. The spectral measurements were collected during the period, 24 June-9 July 2005. The system was set up to collect data each evening at around sunset and ran overnight. As such, only nocturnal measurements are available here.

\subsection{Spectral fitting}

Each averaged ambient spectrum was corrected for electronic offset and dark noise. The net spectra were fit using DOASIS software (Kraus, 2006). HONO was fit in the wavelength region $337-358 \mathrm{~nm}$. The fit scenario included an absorption reference spectrum of HONO (Bongartz et al., 1991), with cross sections reduced by $14.5 \%$ as recommended (Bongartz et al., 1994) and convoluted to the slit function of our spectrometer using a line from the $\mathrm{Hg}$ reference spectrum, $\mathrm{NO}_{2}$ at $294 \mathrm{~K}$ (Vandaele et al., 1998), and the $\left(\mathrm{O}_{2}\right)_{2}$ collision dimer (Hermans et al., 1999). $\mathrm{SO}_{2}$ was fit in the wavelength region 303-312 nm. The fit scenario included a convoluted absorption reference spectrum of $\mathrm{SO}_{2}$ (Vandaele et al., 1994) and $\mathrm{NO}_{2}$ (Vandaele et al., 1998) at $294 \mathrm{~K} . \mathrm{NO}_{2}$ was fit in the wavelength region $422-437.5 \mathrm{~nm}$. The fit scenario included the convoluted reference spectrum of $\mathrm{NO}_{2}$ (Vandaele et al., 1998 ) at 294 K. All fit scenarios included a Xenon-arc lamp spectrum, a Fraunhofer solar reference (if necessary) and a 3 rd order polynomial. Detection limits $(3 \sigma)$ were $0.30 \mathrm{ppb}$ for $\mathrm{HONO}, 0.45 \mathrm{ppb}$ for $\mathrm{SO}_{2}$, and $0.20 \mathrm{ppb}$ for $\mathrm{NO}_{2}$, determined by repetitive determination of a low concentration sample.

\section{Results and discussion}

An overview of the measurements made during the study is given in Fig. 2. The mixing ratio of HONO typically increased rapidly in the evening (sunset: $20: 51 \pm 11$ min PDT) to a steady state value between 0.5 and $1.5 \mathrm{ppb}$, where it remained level until its decline in the morning (sunrise: 05:46 \pm 11 min PDT) due to photolysis. The mixing ratio of $\mathrm{SO}_{2}$ was generally about $1 \mathrm{ppb}$, apart from marine vessel plume incidents during which $\mathrm{SO}_{2}$ increased to as high as $18 \mathrm{ppb}$, highly correlated with $\mathrm{NO}_{2}$. Evidence points to these events being associated with emissions from major commercial ships that were observed passing around the site throughout the study. The levels of $\mathrm{NO}_{2}$ were as high as $50 \mathrm{ppb}$ with higher levels after sunset and before sunrise, indicative of a polluted area. Relative humidity varied between 60 $90 \%$ throughout the study, typical for a marine area. The temperature was at its seasonal maximum, ranging between $25^{\circ} \mathrm{C}$ and $14^{\circ} \mathrm{C}$ at night. Continuous clear to mostly clear and sunny conditions were experienced throughout the majority of the study; with a few incidents of morning haze and a 5 min period of rain on the night of 31 July/1 August.

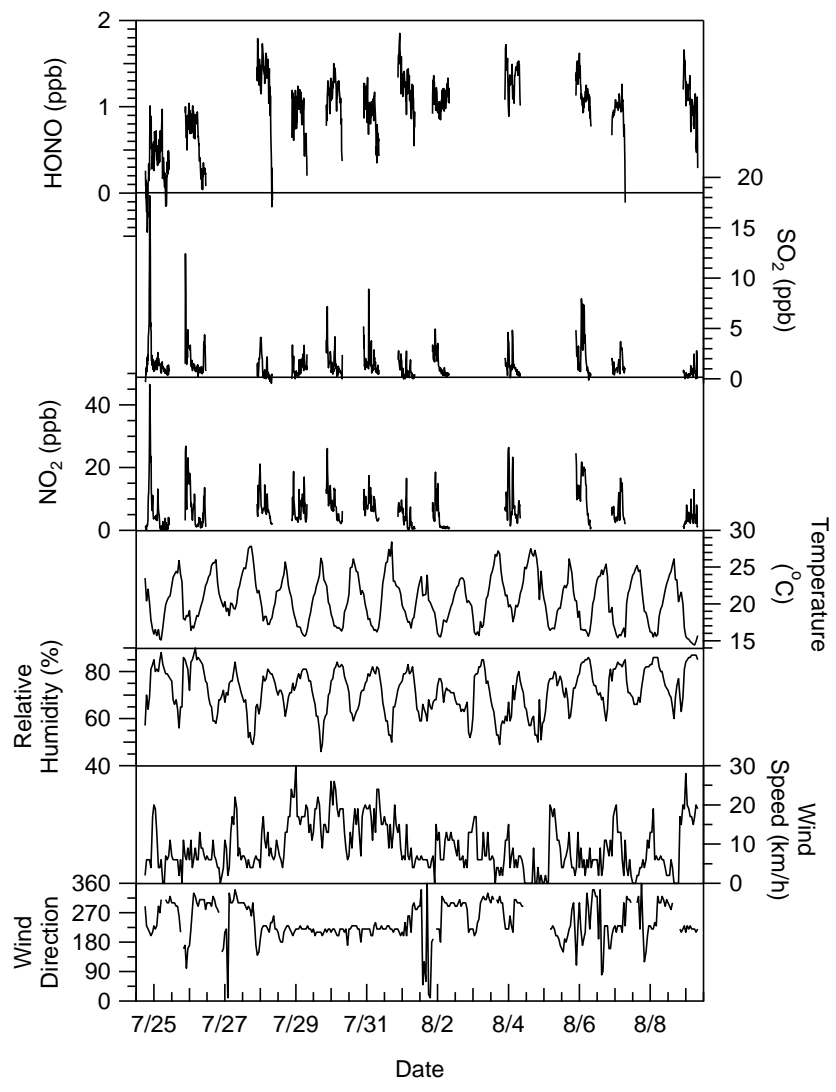

Fig. 2. Chemical and meteorological observations at East Point, Saturna Island.

\subsection{Case study observations of HONO}

Two cases studies are presented to highlight some of general features observed throughout the study. The first was the night of 24/25 July (Fig. 3). The HONO mixing ratio was low shortly before sunset, and rose quickly to just less than $1 \mathrm{ppb}$. It then stabilized at ca $0.5 \mathrm{ppb}$ for the rest of the evening, before depleting after sunrise. The increase in HONO during sunset may appear to be associated with a large increase in $\mathrm{NO}_{2}$ and $\mathrm{SO}_{2}$ during a marine vessel plume event, although we believe this to be coincidental timing. Generally, any changes in HONO during plume events were not statistically significant, and in certain cases, a slight anti-correlation appeared to exist between $\mathrm{NO}_{2}$ and $\mathrm{HONO}$. Levels of $\mathrm{NO}_{2}$ were lowest in the latter part of the night on this day. Despite the low $\mathrm{NO}_{2}$ levels during the latter period, HONO levels remained high apart from the photochemical decrease after sunrise. Two periods of relative chemical and meteorological stability were encountered during the night. The first was between 11:30 p.m. and 02:00 a.m., long after the marine emissions plume was encountered. Chemical levels were constant with $\mathrm{NO}_{2} \sim 3.9 \mathrm{ppb}, \mathrm{SO}_{2} \sim 1.3 \mathrm{ppb}$ and $\mathrm{HONO} \sim 0.50 \mathrm{ppb}$. Winds were from the $\mathrm{SW}$ at $\sim 18 \mathrm{~km} / \mathrm{h}$. Apart from a few small islands, there is mostly open ocean 


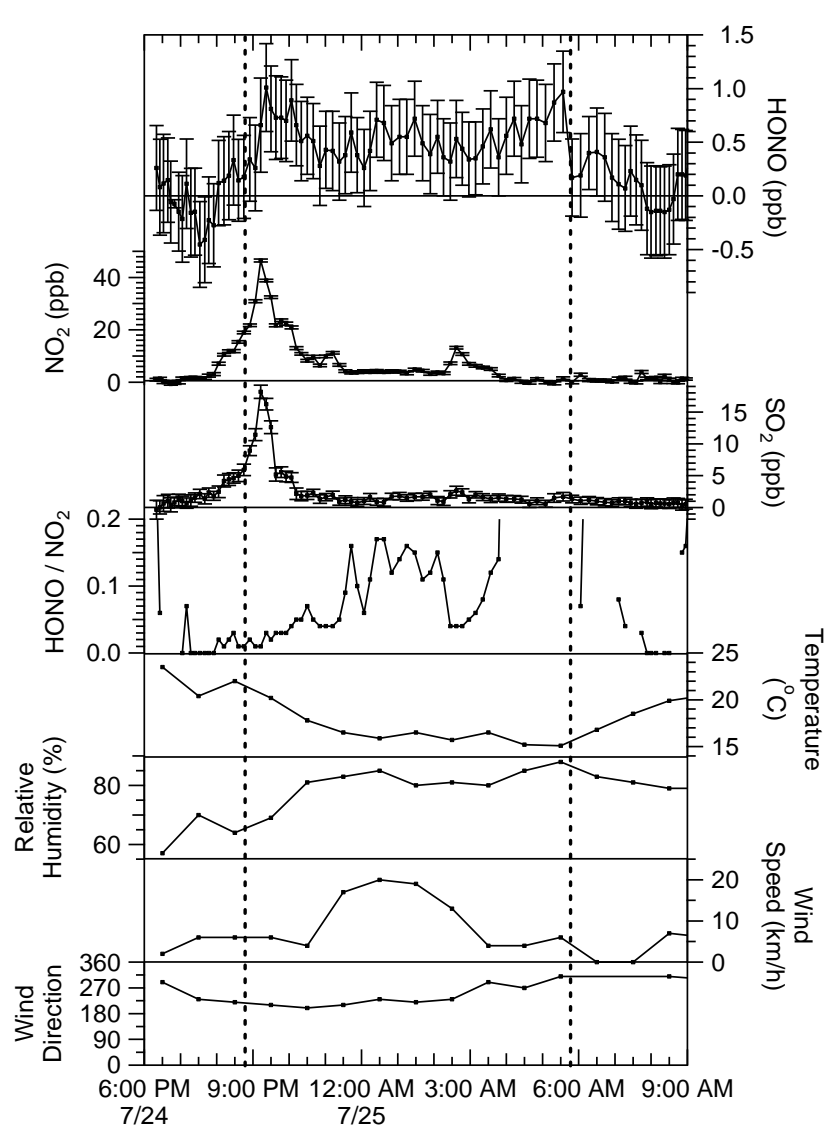

Fig. 3. Nocturnal measurements 24/25 July at East Point, Saturna Island. Vertical dashed lines represent times of sunset and sunrise.

in the SW direction for a distance of $\sim 40 \mathrm{~km}$. This implies that the air mass had traversed the open ocean for at least $2 \mathrm{~h}$ prior to arrival at the site and prior to having encountered any major anthropogenic sources. The average $\mathrm{HONO} / \mathrm{NO}_{2}$ ratio during this period was $0.13(13 \%)$. Between $02: 30$ and 03:30 a.m., an air mass with elevated $\mathrm{NO}_{2}$ arrived as the wind shifted to the west. The HONO remained largely unchanged despite the change in air mass although the $\mathrm{HONO} / \mathrm{NO}_{2}$ ratio dropped to $\sim 0.04(4 \%)$ during this event. The second stable period was experienced after this from $\sim 03: 30$ 05:30 a.m., just before sunrise with winds from the NW and wind speeds $\sim 5 \mathrm{~km} / \mathrm{h}$. During this second period, the pollutant levels were low; average $\mathrm{NO}_{2} \sim 0.40 \mathrm{ppb}, \mathrm{SO}_{2} \sim 1.1 \mathrm{ppb}$. It is likely that the air had travelled from the northwest down the Straight of Georgia over the ocean for a period of hours before impacting the site, and without encountering any major $\mathrm{NO}_{\mathrm{x}}$ sources. The HONO levels were $\sim 0.65 \mathrm{ppb}$ and the $\mathrm{HONO} / \mathrm{NO}_{2}$ ratio was highly variable and uncertain due to the uncertainty in $\mathrm{NO}_{2}$ levels close to the detection limit. The average $\mathrm{HONO}$ and $\mathrm{NO}_{2}$ levels during this second stable period suggest though, that the $\mathrm{HONO} / \mathrm{NO}_{2}$ ratios were greater than $1.0(100 \%)$. Despite the changes in air masses encountered between 11:30 p.m. and 05:30 a.m., HONO lev- els remained largely unperturbed, typical of a pseudo steady state (PSS) and did not appear to be correlated with the $\mathrm{NO}_{2}$ concentration or the source of the air mass. The only common feature between the 3 different air masses transported to the site was their passage over the ocean in the MBL for extended periods of time. The $\mathrm{HONO} / \mathrm{NO}_{2}$ ratio was inversely correlated with $\mathrm{NO}_{2}$ during these times, as HONO was clearly independent of $\mathrm{NO}_{2}$.

The first case presented here was essentially reproduced on another night, 1/2 August (not shown). On that night, the level of HONO levelled off at $\sim 1 \mathrm{ppb}$ within an hour after sunset and remained relatively constant until 07:30 a.m., despite $\mathrm{NO}_{2}$ dropping from $>15 \mathrm{ppb}$ in the early night to $<1 \mathrm{ppb}$ after 01:30 a.m. On that morning, the onset of HONO photolysis was delayed due to hazy conditions and low light levels. For a period of $6 \mathrm{~h}$ (01:3007:30 a.m.) after $\mathrm{NO}_{2}$ dropped by an order of magnitude, the $\mathrm{HONO}, \mathrm{NO}_{2}, \mathrm{SO}_{2}$ and $\mathrm{HONO} / \mathrm{NO}_{2}$ ratios were relatively constant with average ( \pm standard deviation) levels of $1.10( \pm 0.11) \mathrm{ppb} ; 0.90( \pm 0.24) \mathrm{ppb} ; 0.56( \pm 0.24) \mathrm{ppb}$ and $1.83( \pm 0.77)\left(\mathrm{mol} \mathrm{mol}^{-1}\right.$, average ratio), respectively, with wind speeds of $6-13 \mathrm{~km} \mathrm{~h}^{-1}$, and a shift in wind from SW to $\mathrm{NW}$ at $\sim 03: 00$ a.m. Thus high $\mathrm{HONO} / \mathrm{NO}_{2}$ ratios, greater than $100 \%$ were observed, and HONO remained constant for extended periods, even after a significant drop in $\mathrm{NO}_{2}$ levels of one order of magnitude. There were several other examples of this type during the study.

The second night to be presented is in Fig. 4. On this night, winds were persistently from the south west, and several ship plume events were detected, starting with one centered at 09:12 p.m. Again HONO levels rose shortly after sunset, reaching a relatively stable level by $\sim 10 \mathrm{pm}$, and decreased following sunrise. The levels of $\mathrm{NO}_{2}$ decreased progressively throughout the night but did not fall below $2 \mathrm{ppb}$. The HONO/NO 2 ratios were $\sim 0.05$ early in the evening and show a gradual steady increase throughout the night to $\sim 0.40$ at sunrise, coincident with the decrease in $\mathrm{NO}_{2}$ levels, and again supporting the lack of a dependence of the observed $\mathrm{HONO}$ levels on the coincident $\mathrm{NO}_{2}$ levels. A clear anticorrelation exists between $\mathrm{NO}_{2}$ and the $\mathrm{HONO} / \mathrm{NO}_{2}$ ratio as various $\mathrm{NO}_{2}$ plumes were encountered throughout the night, although the HONO levels remained largely unperturbed throughout these events.

All these cases highlight the existence of a HONO PSS that is well established shortly after sunset. After that, HONO levels remain relatively constant regardless of the air mass source, and appear not to be correlated with $\mathrm{NO}_{2}$ to a first approximation, giving rise to an anti-correlation between $\mathrm{HONO} / \mathrm{NO}_{2}$ levels and $\mathrm{NO}_{2}$. The $\mathrm{HONO} / \mathrm{NO}_{2}$ ratios are surprisingly high, starting out with ratios of $0.05-0.13$ early in the evening and rising to levels of $>1.0$ before sunrise. Some of these points will be explored further in the following sections. 
Table 1. Statistical summary of observations during the pseudo steady state period (10:00 p.m.-05:00 a.m.), 24 July-9 August 2005 (432 observations).

\begin{tabular}{lcccccc}
\hline & $\begin{array}{c}\text { 95-th } \\
\text { percentile }\end{array}$ & $\begin{array}{c}\text { 75-th } \\
\text { percentile }\end{array}$ & Average & Median & $\begin{array}{c}\text { 25-th } \\
\text { percentile }\end{array}$ & $\begin{array}{c}\text { 5-th } \\
\text { percentile }\end{array}$ \\
\hline $\mathrm{HONO}(\mathrm{ppb})$ & 1.54 & 1.26 & 1.08 & 1.08 & 0.93 & 0.52 \\
$\mathrm{NO}_{2}(\mathrm{ppb})$ & 19.1 & 10.6 & 7.8 & 6.7 & 3.7 & 0.90 \\
$\mathrm{SO}_{2}(\mathrm{ppb})$ & 4.1 & 1.92 & 1.52 & 1.14 & 0.64 & 0.19 \\
$\mathrm{HONO} / \mathrm{NO}_{2}$ & 1.17 & 0.30 & $\mathrm{NA}$ & 0.155 & 0.093 & 0.048 \\
$T(\mathrm{~K})$ & 294.6 & 292.3 & 291.0 & 290.8 & 289.6 & 288.4 \\
$\mathrm{RH}(\%)$ & 86 & 83 & 77.4 & 79 & 74 & 62 \\
$\mathrm{WS}\left(\mathrm{km} \mathrm{h}^{-1}\right)$ & 24 & 19 & 12.7 & 13 & 6 & 4 \\
\hline
\end{tabular}

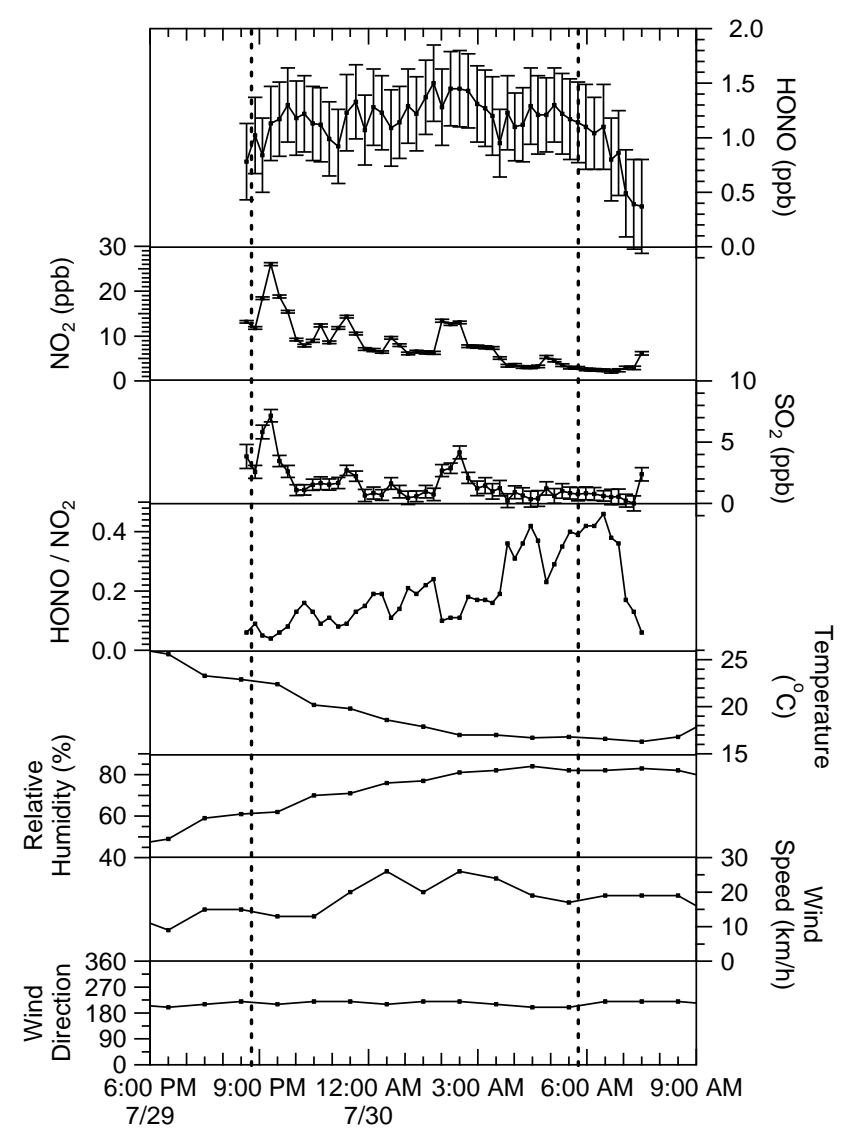

Fig. 4. Nocturnal measurements 29/30 July at East Point, Saturna Island. Vertical dashed lines represent times of sunset and sunrise.

\subsection{Study wide observations of HONO}

The HONO/ $\mathrm{NO}_{2}$ ratio is frequently used as an index of the efficiency of heterogeneous conversion of $\mathrm{NO}_{2}$ to HONO, the rationale being that the production of HONO is first order with the concentration of $\mathrm{NO}_{2}$. A tremendous amount of scatter exists in the relationship between $\mathrm{HONO}$ and $\mathrm{NO}_{2}$ (Fig. 5a), using all data from the study. This scatter has been

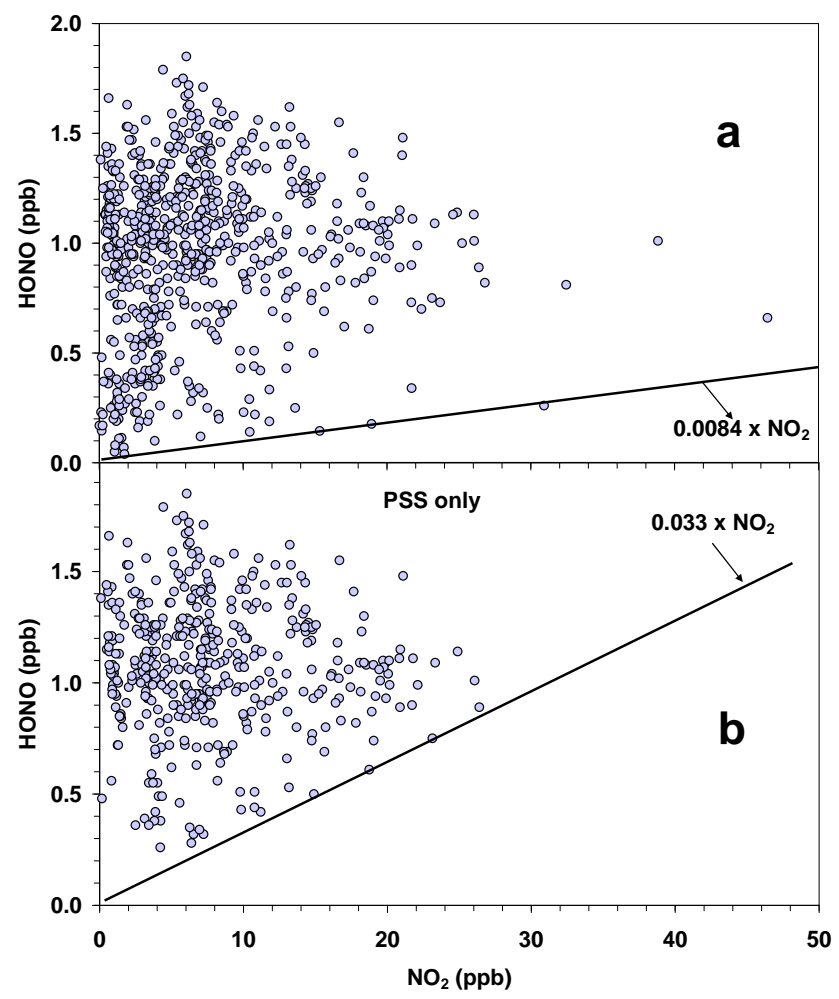

Fig. 5. Relationship between $\mathrm{HONO}$ and $\mathrm{NO}_{2}$ using (a) all data. The lower limit line indicates $\mathrm{HONO} / \mathrm{NO}_{2}=0.0084$, fuel combustion sources (b) only data during the PSS period (10:00 p.m.05:00 a.m.): the lower limit line indicates $\mathrm{HONO} / \mathrm{NO}_{2}=0.033$. See text for details.

seen in several other studies in which HONO is highly correlated to $\mathrm{NO}_{2}$ close to direct sources of $\mathrm{NO}_{\mathrm{x}}$ (urban areas) but significantly less correlation exists between these two pollutants in rural air (Harrison et al., 1996; Zhou et al., 2002). The data in Fig. 5a appears to be bounded on the lower end by a $\mathrm{HONO} / \mathrm{NO}_{2}$ ratio of 0.0084 , similar to that observed in a recent tunnel experiment dominated by diesel vehicles (HONO/NO $\mathrm{N}_{\mathrm{x}}=0.008 \pm 0.001$ ) (Kurtenbach et al., 2001) and similar to that in the nocturnal boundary layer of Kathmandu, 
Nepal (Yu et al., 2009). Thus the lower bound in Fig. 5a may represent the $\mathrm{HONO} / \mathrm{NO}_{\mathrm{x}}$ ratio from diesel sources operating in the region, with $\mathrm{NO}$ titrated quickly to $\mathrm{NO}_{2}$ by $\mathrm{O}_{3}$ in the MBL. Also similar to the study in Nepal, the zero forced regression slope in Fig. 5 was $\mathrm{HONO} / \mathrm{NO}_{2}=0.083 \pm 0.03$ (not shown). What is not similar to that of other studies is that the data in Fig. 5 does not have an upper bound for the $\mathrm{HONO} / \mathrm{NO}_{2}$ ratio, as has been seen in many previous studies in terrestrial regions. For example, it was found that the nocturnal $\mathrm{HONO} / \mathrm{NO}_{2}$ ratio rarely exceeded 0.04 in urban Birmingham (Harrison et al., 1996), 0.035 in Milan after correction (Stutz et al., 2002), 0.075 at two rural sites in England (Harrison et al., 1996), 0.09 in Los Angeles (Harris et al., 1982), 0.03-0.10 at various urban locations in the US, increasing with an increase in relative humidity (Stutz et al., 2004), 0.125 in South-East England (Kitto and Harrison, 1992), 0.13 at various locations in Europe (Lammel and Cape, 1996), and most recently 0.30 in Nepal (Yu et al., 2009). In the present study, the upper $\mathrm{HONO} / \mathrm{NO}_{2}$ ratios were $>1.0$. During such cases, $\mathrm{NO}_{2}$ is present at very low levels and yet HONO remains unperturbed and maintains a constant level. A case in point was presented in Fig. 3 between 03:30-05:30 a.m., as well as the observations discussed for 2 August, 01:30-07:30 a.m. Note that the interpretation of Fig. 5a is complicated since it includes both light and dark periods with variable lifetimes for $\mathrm{HONO}$ with respect to photolysis. For further analysis, we will define the PSS period in this study to be between 10:00 p.m. and 05:00 a.m. PDT, purposely excluding the build up and photolysis periods during sunset and sunrise. The overall statistics for observations in the PSS period are presented in Table 1. The observations of HONO during the PSS fall within a narrow range from $0.5 \mathrm{ppb}$ (5th percentile) to $1.5 \mathrm{ppb}$ (95th percentile). This is true despite the large variability in anthropogenic $\mathrm{NO}_{\mathrm{x}}$ sources in the surrounding region combined with varying transport scenarios. Other sources of variability in the observed HONO levels during the PSS period would include changes in meteorological conditions (temperature, humidity, boundary layer height) as well experimental noise.

When we plot data from the PSS, Fig. 5b, we now have an apparent lower limit of $\sim 0.033$, but still with no upper limit. It is interesting to note that in Milan Italy, Stutz et al. (2002) found that all data (day and night) fell below a $\mathrm{HONO} / \mathrm{NO}_{2}$ line of $x=0.035$ when corrected for direct sources. The interpretation of the upper limit in their study is that it represents the overall conversion efficiency in the reaction, $\mathrm{NO}_{2(\mathrm{~g})} \rightarrow x \mathrm{HONO}_{(\mathrm{g})}$ on the terrestrial surface below. Data falls below the line in their plot due to other losses of HONO such as photolysis. And yet, data we collect during the PSS period fall above such a line. Our best interpretation of Fig. $5 \mathrm{~b}$ at this point is as follows. First, during the PSS period, we have no losses of HONO from the MBL due to photolysis. Second, we argue that the data falling above the line is an indication of a mixture of HONO formation mechanisms in the aqueous system that are both $0^{\circ}$ order and $1^{\circ}$

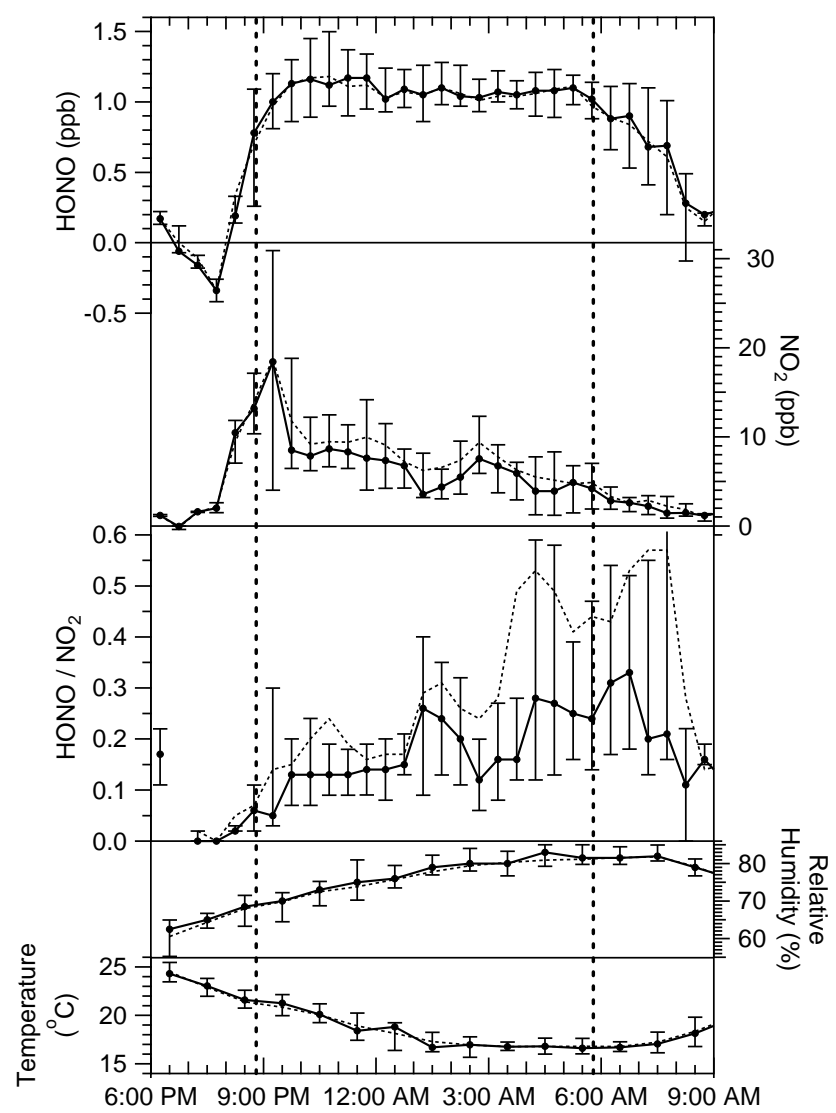

Fig. 6. Study average nocturnal profiles, 24 July-9 August 2005. Shown are median $(\bullet), 25$-th and 75-th percentiles (error bars), and average value (dotted line) within each $30 \mathrm{~min}$ bin. Vertical dashed lines represent times of sunset and sunrise.

order in $\mathrm{NO}_{2}$. The significance of the $x=0.033$ line is not completely understood, but it seems to indicate the HONO to $\mathrm{NO}_{2}$ conversion on dry surfaces (Stutz et al., 2004). It may represent a fundamental $1^{\circ}$ order limit for production of HONO on a surface coated with a single monolayer of water. We will describe the $0^{\circ}$ order mechanism in a future section, but for now, we just comment that the $0^{\circ}$ order mechanism would result from the heterogeneous formation of HONO on a surface that is saturated with $\mathrm{NO}_{2}$ equivalent precursors, followed by reversible distribution of HONO from the surface to the gas phase (vaporization/deposition), without loss from the MBL system. In Fig. 5a, the limit for a zero order process is the vertical $y$-axis.

Study average nocturnal profiles of $\mathrm{HONO}, \mathrm{NO}_{2}$, $\mathrm{HONO} / \mathrm{NO}_{2}$ ratio, relative humidity and temperature presented in Fig. 6, were created by binning all study data into $0.5 \mathrm{~h}$ intervals. The average profile for HONO is similar to that discussed for the case studies, showing a rapid increase after sunset to a PSS level, which is steady throughout the night, with a small discernable decrease with time until sunrise, when HONO photolysis begins. The increase in HONO 
to a PSS level is already started at the point of sunset, and is complete within an hour after sunset, much faster than is typically seen in terrestrial locations. In case studies in urban areas with similar values of $\mathrm{RH}, 60 \%<\mathrm{RH}<100 \%$, the PSS in HONO was not reached until 00:00 a.m. in Nashville, 02:30 a.m. in Houston and 01:00 a.m. in Phoenix, in each case being several hours after sunset (Stutz et al., 2004). The main difference between the environment in the present study and that in the urban environment is the presence of the ocean surface, and to a lesser extent the presence of marine aerosols. One of these factors is responsible for the fast approach to the steady state. The nocturnal profile of $\mathrm{NO}_{2}$ (Fig. 6) indicates a general decrease in $\mathrm{NO}_{2}$ as the night proceeds. The temporal decrease in $\mathrm{NO}_{2}$ could be due to a number of factors including a reduction in anthropogenic $\mathrm{NO}_{2}$ sources, a loss of $\mathrm{NO}_{2}$ to the $\mathrm{NO}_{3} / \mathrm{N}_{2} \mathrm{O}_{5}$ reservoir with heterogeneous conversion to $\mathrm{HNO}_{3}$ and photolabile halogen species (Dentener and Crutzen, 1993; McLaren et al., 2010), loss of $\mathrm{NO}_{2}$ due to heterogeneous formation of $\mathrm{HONO}$, dissolution of $\mathrm{NO}_{2}$ in the ocean, and/or a change in transport patterns during the night. An increase in the $\mathrm{HONO} / \mathrm{NO}_{2}$ ratio through the night is also apparent in Fig. 6, with median levels climbing quickly after sunset to $13.0 \%$ at the beginning of the PSS period (average 22:00-24:00 PDT), but gradually increasing thereafter, reaching $25-30 \%$ by early morning. The 95-th percentiles of $\mathrm{HONO} / \mathrm{NO}_{2}$ ratios at the end of the night are $>1.0$ (Table 1). The implications of these numbers are that they suggest that the mechanism of HONO formation on terrestrial surfaces and on aqueous water are fundamentally related with a gradual increase in the maximum $\mathrm{HONO} / \mathrm{NO}_{\mathrm{x}}$ ratio from 0.03 on surfaces in dry environments (10\% RH) (Stutz et al., 2002, 2004) increasing to maximums of $0.10-0.13$ on surfaces at high relative humidity (Lammel and Cape, 1996; Stutz et al., 2004) and with a continuity on aqueous surfaces observed in this study, with $\mathrm{HONO} / \mathrm{NO}_{2}$ ratios during the PSS observed ranging from 0.13 to $>1.0$. Thus it appears that not only the presence of water ( 1 monolayer of $\mathrm{H}_{2} \mathrm{O}$ at low $\mathrm{RH}$ ) but also the amount of water is important in the HONO formation mechanism. The similarity here is that all surfaces are coated with a minimum of 1 monolayer of water. Since $\mathrm{H}_{2} \mathrm{O}$ is consumed in Reaction (R1), this could be a limiting reagent.

Several reports of HONO in terrestrial locations exist where authors comment on a PSS for HONO on certain nights (Lammel and Cape, 1996; Stutz et al., 2002, 2004; Yu et al., 2009), and it appears to be associated with humid nights (Stutz et al., 2004; Yu et al., 2009). The constant temporal behaviour of HONO in the PSS, implies a balance between sources and sinks of HONO at these times. Stutz presented a simple model to explain the PSS in more detail (Stutz et al., 2004), in which the source of HONO is the heterogeneous reaction of $\mathrm{NO}_{2}$ with the surface (ground or aerosol surface) according to Reaction (R1), and the sink is the first order irreversible deposition of HONO to the surface. Assuming that $\mathrm{NO}_{2}$ is constant with minimal losses, the re- sult is a PSS for both $\mathrm{HONO}$ and the $\mathrm{HONO} / \mathrm{NO}_{2}$ ratio:

$[\mathrm{HONO}]=\frac{\gamma_{\mathrm{NO}_{2} \rightarrow \mathrm{HONO}}}{\gamma_{\mathrm{HONO}}}\left[\mathrm{NO}_{2}\right]$

where $\gamma_{\mathrm{NO}_{2} \rightarrow \mathrm{HONO}}$ is the conversion probability (or uptake coefficient) for the reaction of $\mathrm{NO}_{2}$ on the surface and $\gamma_{\mathrm{HONO}}$ is the uptake coefficient for HONO on the surface. The time constant for the approach to the PSS in the Stutz model ( $\tau=S / V \times v / 4 \times \gamma_{\mathrm{HONO}}$ ) is essentially the inverse of the first order loss constant for deposition of HONO to the surface, $\tau_{\text {dep }}$, and the uptake coefficients were presented as being dependent on relative humidity. Equation (1) predicts that during periods where a PSS exists: (i) the concentration of $\mathrm{HONO}$ is proportional to the concentration of $\mathrm{NO}_{2}$, and (ii) the $[\mathrm{HONO}] /\left[\mathrm{NO}_{2}\right]$ ratio is constant. It also suggests that the level of HONO in the PSS should respond to changes in $\mathrm{NO}_{2}$ with a time constant of $\tau_{\text {dep }}$. Observations in our study suggest that in this polluted aqueous environment, a PSS for HONO is established consistently and quickly almost every night, with a time constant of $<1 \mathrm{~h}$. Further though, the $\mathrm{HONO} / \mathrm{NO}_{2}$ ratio is not constant throughout the night, the steady state $\mathrm{HONO}$ concentration is not proportional to $\mathrm{NO}_{2}$, and the HONO PSS level does not respond to changes in $\mathrm{NO}_{2}$ concentration with a time constant of $\tau_{\text {dep }}$. The HONO PSS level we observe is relatively undisturbed with a change in air mass or a change in $\mathrm{NO}_{2}$ levels by as much as an order of magnitude. These observations lead us to two inescapable conclusions thus far. The first conclusion is that during the PSS period, the source of HONO in the MBL is not proportional to the concentration of $\mathrm{NO}_{2}$. Despite this, a source of HONO must exist. The second conclusion requires more explanation. The general consensus from field and laboratory investigations is that $\mathrm{HONO}$ is lost from the gas phase through deposition to surfaces, which in this environment are coated with water. As the lifetime for deposition of HONO from the PSS is $<1 \mathrm{~h}$, and since the HONO PSS can persist for much longer than this (i.e. $\sim 7 \mathrm{~h}$ ), then the source of the HONO must either be: (i) a reservoir of nitrogen that is significantly larger than the gas phase reservoir of HONO in the MBL and/or (ii) HONO must be recycled into the source reservoir after deposition. Both these conclusions are significant since they modify our current understanding of nocturnal HONO formation. We will return to these points and discuss potential reservoirs of $\mathrm{HONO}$ and/or precursors in a future section.

There is still a chance that the phenomena observed here are specific to the MBL. We do not believe this to be true since a careful examination of previous datasets in terrestrial urban/suburban/rural environments can lead to similar conclusions. We provide a compilation of what we believe to be examples of PSSs of HONO in the nocturnal atmosphere in urban terrestrial environments, from existing literature (Table 2). The examples were compiled either through the authors identification of a nocturnal PSS or "levelling off" for an extended period of time, or through our examination of the 
Table 2. Evidence of nocturnal HONO pseudo steady states in terrestrial locations.

\begin{tabular}{|c|c|c|c|c|c|c|c|c|}
\hline Reference & Location & Date & $\begin{array}{c}\text { Time } \\
\text { (local) }\end{array}$ & $\begin{array}{c}\text { HONO } \\
(\mathrm{ppb})\end{array}$ & $\begin{array}{l}\mathrm{NO}_{2} \\
(\mathrm{ppb})\end{array}$ & $\begin{array}{c}T \\
\left({ }^{\circ} \mathrm{C}\right)\end{array}$ & $\begin{array}{l}\text { RH } \\
(\%)\end{array}$ & Comment \\
\hline Stutz (2004) & Houston, USA & 5 Sep 2000 & $2.5-5.0$ & $0.9-1.1$ & $11-24$ & - & $88-93$ & \\
\hline Stutz (2004) & Nashville, USA & 13 Jul 1999 & $0.0-5.0$ & $0.6-0.9$ & $16-22$ & - & $90-100$ & \\
\hline Stutz (2004) & Phoenix, USA & 26 Jun 2001 & $0.0-5.7$ & $1.2-1.7$ & $15-33$ & - & $65-75$ & $10-139 \mathrm{~m}$ \\
\hline Acker (2004) & Melpitz, Germany & 10 Apr 2000-12 Apr 2000 & $1.0-6.0$ & $0.1-0.2$ & $1.1-2.2$ & $-1-1$ & $70-90$ & 3 nights, PSS uncertain \\
\hline Kleffman (2007) & Wuppertal, Germany & 3 Sep 2004 & $22.5-5.5$ & $1.0-1.2$ & - & - & - & PSS uncertain \\
\hline Yu (2009) & Kathmandu, Nepal & 3 Feb 2003 & $0.0-3.0$ & $0.8-1.4$ & $3-15$ & $4-11$ & $70-100$ & PSS uncertain, $\mathrm{NO}_{\mathrm{x}}$ and $\mathrm{PM}_{10}$ \\
\hline Yu (2009) & Kathmandu, Nepal & 4 Feb 2003 & $1.0-4.0$ & $0.8-1.2$ & $5-9$ & $3-10$ & $80-100$ & sources, $T$ and $\mathrm{RH}$ are range \\
\hline Yu (2009) & Kathmandu, Nepal & 5 Feb 2003 & $1.0-4.0$ & $0.9-1.7$ & $8-15$ & $3-10$ & $80-100$ & for whole study \\
\hline Yu (2009) & Kathmandu, Nepal & 6 Feb 2003 & $1.0-4.0$ & $1.1-1.7$ & $7-15$ & $3-10$ & $80-100$ & \\
\hline This work* & Saturna Is, Canada & 24 Jul 2005-9 Aug 2005 & $22-5.0$ & $0.5-1.5$ & $4-19$ & $15-21$ & $74-86$ & ${ }^{*}$ marine PSS \\
\hline
\end{tabular}

data for periods of constant $\mathrm{HONO}$ during the night which are not perturbed by high local emission sources of $\mathrm{NO}_{\mathrm{x}}$ (i.e. high NO) or high surface area of $\mathrm{PM}_{10}$. As discussed by Stutz (2004), high direct sources can increase the amount of HONO beyond the PSS, albeit temporarily, before HONO returns to the PSS. At this point we will highlight just one example of a PSS that has properties of our MBL PSSs. In Houston on 5 September 2000 (Stutz et al., 2004), after the establishment of a HONO PSS at 02:30 a.m., $\mathrm{NO}_{2}$ levels increase from 02:30-05:30 a.m. by more than 60\% (from 11.0 to $18.3 \mathrm{ppb}$, without increase in NO), although HONO remained almost constant $( \pm 6 \%)$, and the $\mathrm{HONO} / \mathrm{NO}_{2}$ ratio decreased by a factor proportional to the $\mathrm{NO}_{2}$ increase. The independence of the HONO PSS level on $\mathrm{NO}_{2}$ concentration is characteristic of what we have observed and central to our arguments above. This is but one example of a PSS in the urban environment during which HONO is independent of $\mathrm{NO}_{2}$. Arguments of transport can always be invoked to rationalize an individual case, but clearly the case for transport as influencing the PSS (to a first approximation) has been ruled out in the polluted MBL in this study. We suggest that careful examination of PSSs in other urban data sets may result in similar conclusions.

\subsection{Relative humidity and temperature dependence of HONO in PSS}

To explore the dependence of the HONO mixing ratios in the PSS periods, all data collected during the PSS period (22:00-05:00 PDT) are plotted as a function of relative humidity (RH) in Fig. 7, and temperature in Fig. 8. A negative dependence of HONO with relative humidity is obvious (Fig. 7). A casual observation of the data might suggest lack of a dependence when relative humidity is less than $\sim 75 \%$, although two separate regressions for data in the $\mathrm{RH}<75 \%$ and $\mathrm{RH} \geq 75 \%$ regions indicate a statistically significant negative correlation over the whole $\mathrm{RH}$ range (59-90\% RH). It is possible that HONO is coincidentally related to RH through a subtle decrease in HONO throughout the night, and a coincidental temporal change in other parameters as the night

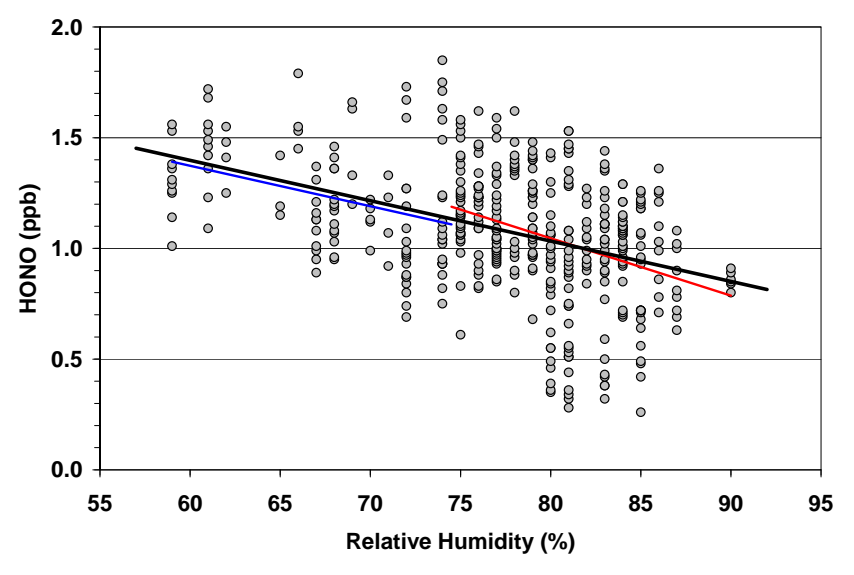

Fig. 7. Relative humidity dependence of HONO measured at Saturna Island during the PSS time period: 22:00-05:00. Black line - linear fit using all data $\left(C_{\mathrm{HONO}}=2.47( \pm 0.35) \mathrm{ppb}\right.$ $\left.-0.0182( \pm 0.0049) * \mathrm{RH} \% ; R^{2}=0.17\right)$. Blue and red lines show linear fit for $\mathrm{RH}<75 \%$ and $\mathrm{RH} \geq 75 \%$, respectively. All negative dependencies are statistically significant at the $95 \%$ confidence level.

proceeds. To rule this out, $\mathrm{HONO}$ vs. $\mathrm{RH}$ regressions were performed on $1 \mathrm{~h}$ binned data from 22:00-05:00, thus removing any temporal relationship. All seven bins indicated a statistically significant negative correlation between $\mathrm{HONO}$ and $\mathrm{RH}$, similar in magnitude to that seen in Fig. 7.

While a negative correlation between HONO and RH is observed, this is not proof of cause and effect. Relative humidity and temperature are not independent, with relative humidity increasing due to a decrease in temperature for a constant amount of water vapor. Thus the observed correlation between HONO and RH could indicate a positive dependence of HONO with temperature through some other physical or chemical mechanism. With current mechanisms in the literature, the link between HONO concentration and RH are thought to be related to increased water content on surfaces, which enhances the heterogeneous formation rate of HONO via Reaction (R1), and it could also enhance the loss rate of HONO from the gas phase on a surface, or into an aqueous 


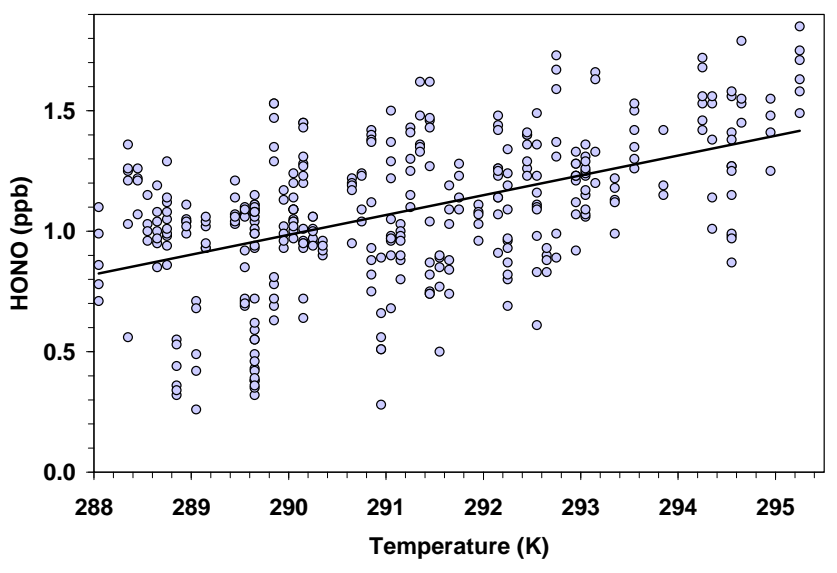

Fig. 8. Temperature dependence of HONO measured at Saturna Island during the PSS time period: 22:00-05:00. The equation of the linear line is $C_{\mathrm{HONO}}=0.082( \pm 0.007) \times T-22.8( \pm 2.1) \mathrm{ppb}$; $R^{2}=0.25$. The positive temperature dependence is statistically significant (95\% confidence level). The corresponding temperature coefficient of the dependence in the middle of the temperature range $(292 \mathrm{~K})$ is $\left(1 / C_{\mathrm{HONO}}\right) d C_{\mathrm{HONO}} / d T=+7.2 \%( \pm 0.6 \%) \mathrm{K}^{-1}$.

layer formed on a surface. These surfaces in general could be the surface at the base of the air column (i.e. ocean), the surface of aerosols, or any anthropogenic/biogenic surfaces available in the air mass. Since the HONO concentration is a balance between sources and losses during the PSS period, for an increase in water on surfaces due to increase in $\mathrm{RH}$, one would expect that an increase in the source rate of HONO would show a positive correlation of HONO with RH, while any increase in the loss of HONO would show a negative correlation of HONO with RH, all else being equal. Since the available surface is dominated by the ocean surface in the MBL, we expect that changes in RH will not significantly change the amount of water available on the surface of the ocean, but it could increase the amount of water available on marine aerosols. Thus, we conclude that the negative correlation of $\mathrm{HONO}$ with RH is either due to increased net loss of $\mathrm{HONO}$ on the surface of, or into the aqueous layer of MBL aerosols, or failing this, there exists a positive correlation between HONO and temperature that is somehow related to the HONO PSS mechanism. We next argue that the latter is true.

The loss of HONO on, or into the aqueous surface of MBL aerosols arising from an increase in $\mathrm{RH}$ would be of significance only if the surface or volume density of $\mathrm{H}_{2} \mathrm{O}$ on MBL aerosols is more significant than the surface or volume density of the ocean in the MBL. Despite a lack of supporting aerosol measurements during this study, these parameters can be reasonably estimated. For example, the total surface and volume density of $\mathrm{H}_{2} \mathrm{O}$ in a typical distribution of deliquesced sea salt aerosols $\left(10 \mu \mathrm{g} \mathrm{m}^{-3}\right)$ at $96 \% \mathrm{RH}$ is $4.3 \times 10^{-5} \mathrm{~m}^{2} \mathrm{~m}^{-3}$ $\left(43 \mu \mathrm{m}^{2} \mathrm{~cm}^{-3}\right)$ and $1.47 \times 10^{-10} \mathrm{~m}^{3} \mathrm{~m}^{-3}\left(147 \mu \mathrm{m}^{3} \mathrm{~cm}^{-3}\right)$, respectively (Chameides and Stelson, 1992). Presuming that the MBL is polluted with a moderate amount of anthropogenic aerosols $\left(10 \mu \mathrm{g} \mathrm{m}^{-3} ; 50 \% \mathrm{H}_{2} \mathrm{O}, d_{p}=0.2 \mu \mathrm{m}\right)$, an additional surface and volume density of $\mathrm{H}_{2} \mathrm{O}$ can be estimated to be $5.5 \times 10^{-4} \mathrm{~m}^{2} \mathrm{~m}^{-3}$ and $9.1 \times 10^{-12} \mathrm{~m}^{3} \mathrm{~m}^{-3}$, respectively. The total surface and volume densities of $\mathrm{H}_{2} \mathrm{O}$ in the MBL aerosols would thus be $5.9 \times 10^{-4} \mathrm{~m}^{2} \mathrm{~m}^{-3}$ and $1.56 \times 10^{-10} \mathrm{~m}^{3} \mathrm{~m}^{-3}$, respectively. We can compare these to the ocean. The geometric surface area density of the ocean surface in a well mixed MBL column of height $H$ is given by $1 / H$; a lower estimate since the MBL may not be well mixed at night (Stutz et al., 2002). The volume density of $\mathrm{H}_{2} \mathrm{O}$ in the ocean available to the MBL column of air above it can be estimated very conservatively to be equal to $t_{\mathrm{SML}} / H$ (at a minimum), where $t_{\mathrm{SML}}$ is the thickness of the aqueous layer in the sea surface microlayer (SML). Using a typical nocturnal marine boundary layer height, $h_{\mathrm{MBL}}=100 \mathrm{~m}$ (Brown et al., 2004) and a typical SML thickness, $t_{\mathrm{SML}}=50 \mu \mathrm{m}$ (Zhang et al., 2006), our minimum estimate of the effective ocean surface and volume densities of $\mathrm{H}_{2} \mathrm{O}$ in the MBL are $0.01 \mathrm{~m}^{2} \mathrm{~m}^{-3}$ and $5 \times 10^{-3} \mathrm{~m}^{3} \mathrm{~m}^{-3}$, respectively. These numbers are more than an order of magnitude $(\times 17)$ and seven orders of magnitude $\left(3 \times 10^{7}\right)$ greater than those available on MBL aerosols. Thus, we conclude that increased surface or volume density of aerosols coincident with an increase in $\mathrm{RH}$ is negligible compared to an unchanging ocean, having a negligible effect on HONO deposition loss. This implies that the negative correlation between HONO and RH is coincidental with a positive correlation between HONO and temperature, that is somehow related to the HONO PSS mechanism.

The positive relationship between HONO and temperature evident in Fig. 8 is statistically significant at the $95 \%$ confidence level. The correlation coefficient $\left(R^{2}=0.25\right)$ accounts for more of the variance in HONO observations than does the HONO vs. RH dependence $\left(R^{2}=0.17\right)$. Using a linear regression, the corresponding temperature coefficient $\left(\left(1 / P_{\mathrm{HONO}}\right) \times d P_{\mathrm{HONO}} / d T\right)$ of the dependence indicates that HONO increases by $+7.2 \pm 0.6 \% \mathrm{~K}^{-1}$ in the temperature region. As we did for RH, HONO vs. $T$ regressions were performed on $1 \mathrm{~h}$ binned data to rule out other temporal processes that may occur at night. A statistically significant $(>95 \%)$ correlation between HONO and temperature was still observed in all seven bins (not shown), similar to that shown in Fig. 8.

There are many temperature dependent processes that could give rise to the temperature dependence of HONO over the ocean surface. Of interest is a comparison to the temperature dependence of a gas phase-aqueous phase equilibrium process such as that dictated by the temperature dependent Henry's Law coefficient, $H(T)$ for the solubility of HONO in water:

$$
H(T)=\frac{\left[\mathrm{HONO}_{(\mathrm{aq})}\right.}{P_{\mathrm{HONO}}}=H^{\circ} \exp \left(\frac{\Delta H_{\mathrm{vap}}}{R}\left(\frac{1}{T}-\frac{1}{T^{\circ}}\right)\right)
$$


where $P_{\mathrm{HONO}}$ is the partial pressure of $\mathrm{HONO}, H^{\circ}$ is the Henry's Law constant at reference temperature $T^{\circ}, \Delta H_{\text {vap }}$ is the enthalpy of vaporization of $\mathrm{HONO}_{(\mathrm{aq})}$, and $R$ is the gas constant. For this equilibrium process, the temperature coefficient of HONO would be given by:

$$
\frac{1}{P_{\mathrm{HONO}}} \frac{d P_{\mathrm{HONO}}}{d T}=\frac{\Delta H_{\mathrm{vap}}}{R} \frac{1}{T^{2}}
$$

The value of $H^{\circ}(298 \mathrm{~K})$ and $\Delta H_{\mathrm{vap}} / R$ in Eq. (2) are $49 \pm 1 \mathrm{~mol} \mathrm{~L}^{-1} \mathrm{~atm}^{-1}$ and $4900 \pm 150 \mathrm{~K}$, respectively in water (Park and Lee, 1988; Becker et al., 1996). Using the ocean surface temperature in the Strait of Georgia in July $\left(10-15^{\circ} \mathrm{C}\right)$, the temperature coefficient of $P_{\mathrm{HONO}}$ predicted by Eq. (3) would be: $+6.0 \pm 0.2 \% \mathrm{~K}^{-1}$. This is close to that observed in Fig. 8, despite that air in the MBL and the ocean are not in thermal equilibrium, and that the Henry's Law constant in sea water may deviate from that in water. Another way to express the temperature dependence is to determine the value of $\Delta H_{\text {vap }}$. This was achieved by a least squares regression of the relationship between $\ln P_{\text {HONO }}$ vs. $1 / T$, the slope of which is equivalent to $-\Delta H_{\mathrm{vap}} / R$. The regression yields $\Delta H_{\text {vap }}(\mathrm{HONO})=55.5 \pm 5.4 \mathrm{~kJ} \mathrm{~mol}^{-1}$, close to $\Delta H_{\text {vap }}=40.7 \pm 1.2 \mathrm{~kJ} \mathrm{~mol}^{-1}$ determined from the literature value of $H(T)$ in pure water. While this is not proof of the process, the temperature dependence of HONO PSS observations is at least consistent with an equilibrium process releasing HONO from the surface of the ocean.

\subsection{Potential aqueous reservoirs of HONO}

As discussed in Sect. 3.2, one of the conclusions from our observations was that there exists either a reservoir of HONO (or precursors) in the polluted MBL that is significantly larger than the gas phase reservoir or, HONO must be recycled into the source reservoir after deposition. We now address three possible aqueous reservoirs in the MBL: (i) bulk water in the sea surface microlayer, (ii) aerosols in the MBL, (iii) the air-sea surface interface.

There are suggestions that storage of HONO or nitrite on aqueous surfaces can be a source for daytime HONO in the early morning (Zhou et al, 2002; Acker et al., 2004; He et al., 2006). This suggests the aqueous phase may be a significant reservoir. In the PSS model presented by Stutz (2004), the ultimate fate of HONO that deposits was not expressed explicitly. While there is evidence that HONO can deposit to laboratory surfaces releasing NO in a heterogeneous reaction (Lammel and Cape, 1996; Finlayson-Pitts et al., 2003; Stutz et al., 2004), it is also likely that HONO at the air-aqueous interface will dissolve if the surface is aqueous, containing more than just a few monolayers of water (Mertes and Wahner, 1995)

$$
\mathrm{HONO}_{(\mathrm{g})} \rightarrow \mathrm{HONO}_{(\mathrm{aq})}
$$

In the case of Reaction (R1) being the source of HONO, $\mathrm{HNO}_{3}$ that is produced will also dissolve resulting in further acidification. The $\mathrm{HONO}_{(\mathrm{aq})}$ would subsequently ionize:

$\mathrm{HONO}_{(\mathrm{aq})}+\mathrm{H}_{2} \mathrm{O}(\mathrm{l}) \rightarrow \mathrm{H}_{3} \mathrm{O}^{+}{ }_{(\mathrm{aq})}+\mathrm{NO}_{2}^{-}{ }_{(\mathrm{aq})}$

dictated by the acid dissociation constant of $\mathrm{HONO}_{(\mathrm{aq})}$, $K_{\mathrm{a}}$, and $\mathrm{pH}$. Total nitrite $\left([\mathrm{N}(\mathrm{III})]=[\mathrm{HONO}]_{(\mathrm{aq})}+\left[\mathrm{NO}_{2}^{-}\right]_{(\mathrm{aq})}\right)$ would build up in the aqueous reservoir to the point where the reservoir becomes a source of HONO to the gas phase,

$\mathrm{HONO}_{(\mathrm{aq})} \rightarrow \mathrm{HONO}_{(\mathrm{g})}$

At the point where the rate of Reactions (R2) and (R4) are equal, we have dynamic equilibrium dictated by the Henry's Law constant (Eq. 2). If equilibrium is reached, the total concentration of $\mathrm{N}(\mathrm{III})$ in the water reservoir would be given by:

$[\mathrm{N}(\mathrm{III})]=P_{\mathrm{HONO}} H\left(1+\frac{K_{\mathrm{a}, \mathrm{HONO}}}{\left[\mathrm{H}^{+}\right]}\right)$

If the reservoir is the ocean, $\mathrm{N}(\mathrm{III})$ would be contained in the sea surface microlayer (SML), the top $\sim 50 \mu$ m of the ocean that is dynamically isolated from the underlying ocean. The SML is frequently enriched in nutrients, biota, organic matter and anthropogenic pollutants. The SML can have different physiochemical properties than the underlying ocean and can serve as a source/sink for materials in the atmosphere (Hardy, 1982). Enhancement of pollutants in the SML with a sharp gradient in concentration and physiochemical properties at the base of the SML has been observed (Zhang et al., 1998, 2006). The underlying ocean also contains N(III), although it is dynamically separate from the SML through a diffusion barrier at the SML/subsurface layer interface.

The concentration of N(III) contained in the SML reservoir at equilibrium would depend on $\mathrm{pH}$, temperature and SML thickness. At equilibrium, the molar fraction of N(III) stored in the SML reservoir would be given by:

$$
f_{\mathrm{SML}}=\frac{N_{\mathrm{NIII}, \mathrm{SML}}}{N_{\mathrm{NIII}, \mathrm{SML}}+N_{\mathrm{HONO}, \mathrm{MBL}}}=\frac{1}{1+\frac{h_{\mathrm{MBL}}}{R T H t_{\mathrm{SML}} \times\left(1+\frac{K_{\mathrm{a}}}{\left[\mathrm{H}^{+}\right]}\right)}}
$$

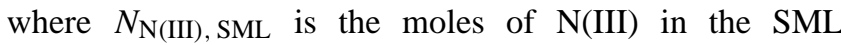
of thickness $t_{\mathrm{SML}}, N_{\mathrm{HONO}}, \mathrm{MBL}$ is the moles of $\mathrm{HONO}$ in the MBL with effective boundary layer height $h_{\mathrm{MBL}}$. Using an unperturbed ocean $\mathrm{pH}=8.1$ in the SML, $t_{\mathrm{SML}}=50 \mu \mathrm{m}, \quad h_{\mathrm{MBL}}=100 \mathrm{~m}, \quad T=290 \mathrm{~K}, \quad K_{\mathrm{a}}=5.1 \times 10^{-4}$, $H(T)=76 \mathrm{M} \mathrm{atm}^{-1}$, Eq. (5) predicts that $98 \%$ of the N(III) would be partitioned in the ocean SML, independent of the partial pressure of HONO in the gas phase. Thus, the SML, at equilibrium with the ocean, could be a significant reservoir of HONO. However, using Eq. (4) and the median nocturnal HONO mixing ratio of $\sim 1 \mathrm{ppb}$, the concentration of $\mathrm{N}(\mathrm{III})$ in the SML at equilibrium would be $4.9 \times 10^{-3} \mathrm{M}$. This is significantly higher than reports of concentrations of N(III) measured in the SML $(<2 \mu \mathrm{M})$ (Zafiriou and True, 1979; 
Zhang et al., 2001, 2006), or the highest N(III) measured in the SML, $9 \mu \mathrm{M}$ (Grasshoff, 1975). Only slight enhancements of $\mathrm{N}(\mathrm{III})$ and $\mathrm{N}(\mathrm{V})$ have been reported in the polluted Bay of Hong Kong (Zhang et al., 2001), and only a slight acidification of the SML compared to the underlying ocean has been recorded ( $-0.2 \mathrm{pH}$ units) (Zhang et al., 2006). Despite this, it is currently unclear how low the $\mathrm{pH}$ of the SML could be in a polluted region such as the Strait of Georgia. If we change the $\mathrm{pH}$ to 7.0 , we predict from Eq. (5), $f_{\mathrm{SML}}=0.82$ and $[\mathrm{N}(\mathrm{III})]=4 \times 10^{-4} \mathrm{M}$. In this extreme acidification case, [N(III)] is still two to three orders of magnitude larger than what has been reported in the literature. Values of $H_{\mathrm{HONO}}$ in seawater are unavailable, and it is likely smaller than $H$ in pure water used here due to the salt effect, but it is unlikely to be more than a factor of 2 smaller if it behaves similar to most other small molecules. It is unclear what effect the natural organic film (lipids and fatty acid material) on the surface of the SML will have on air/sea exchange and other physiochemical properties. Despite these uncertainties, evidence suggests that bulk seawater contained in the SML is significantly under saturated in $\mathrm{N}(\mathrm{III})$ with respect to the atmospheric HONO we measure during PSS periods, and as such, the bulk alkaline ocean would be a net sink for HONO in the gas phase in this region, not a source.

The second potential reservoir to address is aerosols. Sea salt aerosols are likely deliquesced in this region as the $\mathrm{RH}$ never fell below the efflorescence relative humidity of sea salt, 43-48\% (Tang et al., 1997). We calculate the amount of HONO that could dissolve in marine aerosols and the fraction, $f_{\text {aerosol }}$, of HONO present in this reservoir compared to the total amount in the combined gas/aerosol reservoir. We presume that HONO in the gas phase comes to equilibrium with water in the aerosol phase. Using a generously alkaline aerosol $\mathrm{pH}=8.5$ (Chameides and Stelson, 1992) for sea salt aerosols, the same values for $H, T$, and $K_{\mathrm{a}}$ as previous, and our previous estimate of the volume density of $\mathrm{H}_{2} \mathrm{O}$ in the marine aerosols, $1.56 \times 10^{-10} \mathrm{~m}^{3} \mathrm{~m}^{-3}$, we calculate $f_{\text {aerosol }}=0.038$, and the gas phase equivalent of $40 \mathrm{pptV}$ of N(III) that would exist in the aerosol phase. This is a minor reservoir in comparison to gas phase HONO, and would become significantly smaller as $\mathrm{pH}$ decreases. Observations of particulate nitrite and gas phase HONO in terrestrial regions also suggest that aerosol is a minor reservoir of $\mathrm{N}$ (III) compared to the gas phase (Lammel and Cape, 1996). We conclude that the bulk water present in aerosols could not support the PSS we are observing.

The third reservoir we address is the surface of the aqueous layer itself, which could be the surface of the ocean, lakes, deliquesced aerosols and wet terrestrial surfaces. In the MBL, the ocean surface dominates as discussed previously. Current mechanisms suggest that nocturnal HONO formation occurs at surfaces coated with at least a monolayer of $\mathrm{H}_{2} \mathrm{O}$. Lammel (1999) suggested that the formation begins with a molecule of $\mathrm{NO}_{2}$ adsorbing to a molecule of water either chemisorbed to the surface $\left(\mathrm{S}-\mathrm{OH}_{2}\right)$, or adsorbed to another surface molecule of water $\left(\mathrm{S}-\mathrm{OH}_{2} \cdot \mathrm{H}_{2} \mathrm{O}\right)$.

$$
\begin{aligned}
& \mathrm{S}-\mathrm{OH}_{2}+\mathrm{NO}_{2} \rightarrow \mathrm{S}-\mathrm{OH}_{2} \cdot \mathrm{NO}_{2} \\
& \mathrm{~S}-\mathrm{OH}_{2} \cdot \mathrm{H}_{2} \mathrm{O}+\mathrm{NO}_{2} \rightarrow \mathrm{S}-\mathrm{OH}_{2} \cdot \mathrm{H}_{2} \mathrm{ONO}_{2}
\end{aligned}
$$

In a similar mechanism, Finlayson-Pitts proposed that the $\mathrm{HONO}$ formation begins with adsorption of a dimer of $\mathrm{NO}_{2}$, $\mathrm{N}_{2} \mathrm{O}_{4}$, to the surface film, that is more highly stabilized by two water molecules than one. In a model similar to that presented previously (Mertes and Wahner, 1995), we propose that the first step of the mechanisms could also occur on the surface of bulk aqueous water, $\left(\mathrm{H}_{2} \mathrm{O}\right)_{\infty} \cdot \mathrm{H}_{2} \mathrm{O}$

$$
\begin{aligned}
& \left(\mathrm{H}_{2} \mathrm{O}\right)_{\infty} \cdot \mathrm{H}_{2} \mathrm{O}+\mathrm{NO}_{2} \rightarrow\left(\mathrm{H}_{2} \mathrm{O}\right)_{\infty} \cdot \mathrm{H}_{2} \mathrm{O} \cdot \mathrm{NO}_{2} \\
& \left(\mathrm{H}_{2} \mathrm{O}\right)_{\infty} \cdot 2 \mathrm{H}_{2} \mathrm{O}+\mathrm{N}_{2} \mathrm{O}_{4} \rightarrow\left(\mathrm{H}_{2} \mathrm{O}\right)_{\infty} \cdot 2 \mathrm{H}_{2} \mathrm{O} \cdot \mathrm{N}_{2} \mathrm{O}_{4}
\end{aligned}
$$

In either case, the maximum density of $\mathrm{NO}_{2}$ units that could be adsorbed on the surface is equal the maximum density of water molecules at the surface. For a geometrically flat aqueous surface, one can calculate the water molecule radius, $r_{\mathrm{H}_{2} \mathrm{O}}$, cross sectional area, $A_{\mathrm{H}_{2} \mathrm{O}}$, and surface density of water molecules, $S_{\mathrm{H}_{2} \mathrm{O}}=1 / A_{\mathrm{H}_{2} \mathrm{O}}$, to be: $r_{\mathrm{H}_{2} \mathrm{O}}=1.9 \times 10^{-10} \mathrm{~m}$, $A_{\mathrm{H}_{2} \mathrm{O}}=1.2 \times 10^{-19} \mathrm{~m}^{2}$ and $S_{\mathrm{H}_{2} \mathrm{O}}=8.6 \times 10^{18} \mathrm{~mol} \mathrm{~m}^{-2}$. The equivalent $\mathrm{NO}_{2}$ surface density, $\mathrm{S}_{\mathrm{NO}_{2}}^{*}$, if all the $\mathrm{NO}_{2}$ in a well mixed MBL were brought to the ocean surface is given by:

$S_{\mathrm{NO}_{2}}^{*} \equiv \frac{P}{R T} C_{\mathrm{NO}_{2}} h_{\mathrm{MBL}}$

where $C_{\mathrm{NO}_{2}}$ is the $\mathrm{NO}_{2}$ mixing ratio, all else previously defined. The amount of nitrogen required to completely saturate the ocean water surface with a monolayer is obtained by equating $S_{\mathrm{NO}_{2}}=S_{\mathrm{H}_{2} \mathrm{O}}$; we predict $C_{\mathrm{NO}_{2}}=3.4 \mathrm{ppb}$, presuming standard temperature and pressure and a $\sim 100 \mathrm{~m}$ MBL height. Thus the upper limit to the ocean surface reservoir under these conditions would be the equivalent of about $\sim 3 \mathrm{ppb}$ of nitrogen, depending on the actual MBL height. If those precursors reacted by Reaction (R1) until they reach a PSS, $\sim 1.0 \mathrm{ppb}$ HONO would be produced in the gas phase. Ignoring excess $\mathrm{NO}_{2}$ in the gas phase, the maximum fraction of HONO precursors existing on the surface in the MBL for this type of surface reservoir system, would be $f_{\text {surface }}=77 \%$ (given our simple parameters). While this potential upper limit to the reservoir is reasonably large, if the HONO that subsequently deposits is lost from the system, the nitrogen in the surface/gas system would be depleted at a rate of $[\mathrm{HONO}] / \tau_{\text {dep }}$. The surface-gas system could be replenished with gas phase $\mathrm{NO}_{2}$ as the loss occurs. But if $\mathrm{NO}_{2}$ is zero, the combined surface/gas phase nitrogen reservoir would be depleted with a time constant, $\tau_{\text {surface }}=\tau_{\text {dep }} /(1-f)$. Using $\tau_{\text {dep }}=1 \mathrm{~h}$, we would predict $\tau_{\text {surface }}=4.4 \mathrm{~h}$, as an upper limit. We almost had such a case on the morning of 2 August (discussed previously), where the PSS remained stable for $6 \mathrm{~h}$, despite the mixing ratio of $\mathrm{NO}_{2}$ falling from $>15 \mathrm{ppb}$ to $<1.0 \mathrm{ppb}$. Although $\mathrm{NO}_{2}$ was not zero, the absence of any observable decline in the HONO PSS level during this period 
still leads us to believe that if a surface system is generating HONO in the PSS, the HONO that deposits must be recycled into the surface reservoir.

We conclude this section by saying that the aqueous airwater interface at the surface of the ocean, perhaps confined to the top monolayer of water $(0.4 \mathrm{~nm}$ thick), but thinner than the thickness of the SML, is the most likely reservoir for $\mathrm{NO}_{2}$ (or its equivalent precursors) to produce $\mathrm{HONO}$ via Reaction (R1) in sufficient quantities to support the PSS of HONO that we observe in the MBL. As with any surface based mechanism, this sea surface nanolayer (SNL), would be chemically active through its ability to provide a medium that achieves extremely high surface densities where precursor species can react at high rates. Although we cannot prove through our observations that a monolayer of $\mathrm{NO}_{2}$ or precursors would exist, the surface tension of water could support a monolayer of precursors (just as the surface tension of water can support the weight of a water spider), if there is a strong adhesive force of attraction between $\mathrm{NO}_{2}$ (or equivalent) and surface water molecules, but less than the cohesive force of attraction between water bound to itself. Only certain molecules would fulfill this requirement. A more thorough discussion of this topic is beyond the scope of this work.

\subsection{A conceptual model for HONO formation on aqueous surfaces}

We summarize some of our conclusions on the PSS of HONO in the MBL thus far:

1. The PSS of HONO in the polluted MBL is characterized by an extended time period during which $d[\mathrm{HONO}] / d t \approx 0$. It begins to form just before sunset and is usually fully formed within an hour after sunset or faster, faster than seen in terrestrial locations. The levels of HONO in the PSS are similar to that seen in several terrestrial locations; $\sim 0.5-2.0 \mathrm{ppb}$; although there is a current lack of temperature and other data to support better analysis.

2. During the period of the PSS, HONO is frequently independent of $\mathrm{NO}_{2}$, signifying a formation process that is $0^{\circ}$ order in $\mathrm{NO}_{2}$, suggestive of a saturated surface reaction system. The median $\mathrm{HONO} / \mathrm{NO}_{2}$ ratios increase with time from 0.13 (lower limit 0.03) to 0.30 (upper limit >1.0) from the beginning to the end of the PSS period. The continuity of these numbers from those on terrestrial surfaces (maximum 0.03 at low RH to maximum $0.10-0.13$ at high RH) suggest that the HONO formation mechanism is related on all surfaces, with the amount of $\mathrm{H}_{2} \mathrm{O}$ being either a limiting agent, or playing some other fundamental role.

3. $P_{\mathrm{HONO}}$ in the PSS is largely independent of air mass and transport direction, signifying that the PSS is character- istic of the MBL in the region, where the surface of the ocean is the dominating surface.

4. The levels of HONO during the PSS period show a statistically significant negative correlation with $\mathrm{RH}$ over the range $\mathrm{RH}=60-90 \%$, that is only coincidentally related to the HONO PSS levels, through the negative $T-$ $\mathrm{RH}$ relation for water in air.

5. The levels of HONO during the PSS period show a statistically significant positive correlation with temperature. The correlation indicates a temperature coefficient $\left(1 / P_{\mathrm{HONO}}\right)\left(d P_{\mathrm{HONO}} / d T\right)=+7.2 \pm 0.6 \% \mathrm{~K}^{-1}$. If all of this temperature dependence is associated with a surface activation process of $\mathrm{HONO}$, the enthalpy of the process that releases HONO from the SNL would be $\Delta H_{\mathrm{SNL}}=55.5 \pm 5.4 \mathrm{~kJ} \mathrm{~mol}^{-1}$, slightly larger than the $\Delta H_{\text {vap }}=40.7 \pm 1.2 \mathrm{~kJ} \mathrm{~mol}^{-1}$ for HONO vaporization from pure water.

6. The bulk alkaline aqueous phase of the SML and sub layers of the ocean are very unlikely to be a reservoir of $\mathrm{N}(\mathrm{III})$ that could act as a net source of HONO to the MBL based upon current literature of [N(III)] and $\mathrm{pH}$ in the SML. The bulk aqueous phase of marine aerosols are also an unlikely reservoir of N(III) that could act as a net source of HONO to the MBL.

7. The top monolayer of water at the air-sea surface interface could represent a significant reservoir of nitrogen precursors for HONO formation, if the monolayer was saturated with $\mathrm{NO}_{2}$ and/or related nitrogen precursors and products $\left(\mathrm{N}_{2} \mathrm{O}_{4}, \mathrm{ONONO}_{2}, \mathrm{NO}^{+} \mathrm{NO}_{3}^{-}, \mathrm{HONO}\right.$, $\mathrm{HNO}_{3}$ ). This sea surface nanolayer (SNL) would be very acidic through the generation of nitric acid. A single report of $\mathrm{NO}_{3}^{-}$and $\mathrm{NO}_{2}^{-}$measurements in the surface microlayer (SML) and sublayers of polluted Daya Bay near Hong Kong (Zhang and et al., 2001) indicate average enhancements of $2.83 \mu \mathrm{M}\left(\mathrm{NO}_{3}^{-}\right)$and $0.05 \mu \mathrm{M}$ $\left(\mathrm{NO}_{2}^{-}\right)$, perhaps a sign of faster transport of $\mathrm{HNO}_{3}$ from the surface or higher $\mathrm{HNO}_{3} / \mathrm{HONO}$ density at the surface of the ocean.

Thus far, we have not discussed a detailed mechanism for HONO formation. Mertes and Wahner (1995) presented a model for $\mathrm{NO}_{2}$ hydrolysis via Reaction (R1) on experimental aqueous surfaces that used the concept of a surface layer separate from the bulk liquid phase. In an extensive review of all studies to date, Lammel (1999) suggested a surface based formation mechanism and attempted to parameterize the formation of HONO on surfaces according to the following formula:

$\frac{d[\mathrm{HONO}]}{d t}=$
$a\left[\mathrm{NO}_{2}\right]\left\{\left[\left(\frac{S}{V}\right)_{\text {dry }}+\left(\frac{S}{V}\right)_{\text {aqueous }}\right] k_{\text {het } 1}+\left(\frac{S}{V}\right)_{\text {wet }} k_{\text {het } 2\left[\mathrm{H}_{2} \mathrm{O}\right]}\right\}$

Atmos. Chem. Phys., 11, 3243-3261, 2011 
with different parameterizations for dry (dry laboratory and ambient surfaces), wet (humid surfaces), and aqueous (bulk water) surfaces, and $a=0.5$ from Reaction (R1). It predicts a $\mathrm{HONO}$ formation that is $0^{\circ}$ order in $\mathrm{H}_{2} \mathrm{O}$ for dry and aqueous surfaces (noting that dry surfaces contain a monolayer of $\mathrm{H}_{2} \mathrm{O}$ ) and $1^{\circ}$ order in $\mathrm{H}_{2} \mathrm{O}$ for humid surfaces, and a rate that is $1^{\circ}$ order in $\mathrm{NO}_{2}$ for all three surface types. Following from Reaction (R6), the main reaction step to produce HONO proposed by Lammel (1999) is:

$$
\mathrm{S}-\mathrm{OH}_{2} \cdot \mathrm{H}_{2} \mathrm{ONO}_{2}+\mathrm{NO}_{2} \rightarrow \mathrm{SS}-\mathrm{OH}_{2} \cdot \mathrm{HONO}_{2}+\mathrm{HNO}_{2}
$$

Finlayson-Pitts (2003) presented an integrated mechanism for HONO formation on surface films. The detailed mechanism suggested the formation of $\mathrm{N}_{2} \mathrm{O}_{4}$ in the gas phase, followed by uptake of $\mathrm{N}_{2} \mathrm{O}_{4}$ onto the surface film (dry or humid). The $\mathrm{N}_{2} \mathrm{O}_{4}$ isomerizes to asymmetric $\mathrm{ONONO}_{2}$ through reaction with $\mathrm{H}_{2} \mathrm{O}$, which autoionizes to the $\mathrm{NO}^{+} \mathrm{NO}_{3}^{-}$complex in the supporting layer of $\mathrm{H}_{2} \mathrm{O}$. The complex then reacts with water to generate surface adsorbed $\mathrm{HNO}_{3}$ and surface HONO. The surface HONO escapes in part to the gas phase, and is presumably reversible. It was also suggested that in highly acidic surfaces, $\mathrm{HNO}_{3}$ can generate $\mathrm{NO}_{2}^{+}$, which reacts with $\mathrm{HONO}$ to produce NO that escapes from the surface. The rate of formation of HONO in this mechanism was overall $1^{\circ}$ order in $\mathrm{NO}_{2},+2^{\circ}$ due to formation of $\mathrm{N}_{2} \mathrm{O}_{4}$ and $-1^{\circ}$ due to back reaction of $\mathrm{NO}_{2}$ with $\mathrm{ONONO}_{2}$ to produce $\mathrm{N}_{2} \mathrm{O}_{4}$.

Based upon all the observations and conclusions above, and with considerable aid from previous literature, we can now provide a conceptual model for HONO formation in aqueous systems. The model can explain the PSS state we observe in the MBL that is also frequently seen in terrestrial regions on nights that are humid enough to produce condensed water. The model is presented in Fig. 9, illustrating conceptually the mechanism operating in $1^{\circ}$ order and $0^{\circ}$ order $\left(\right.$ in $\mathrm{NO}_{2}$ ) generation of HONO. In the model, a sea surface nanolayer (SNL) (or surface nanolayer/surface film in urban areas) develops after exposure of the aqueous surface to $\mathrm{NO}_{2}$ or its equivalent precursors. The SNL is 1 to $n$ monolayers $\left[t_{\mathrm{SNL}}=n \times 0.38 \mathrm{~nm}\right.$ ], where the total thickness is significantly less than the thickness of the SML $(\sim 50 \mu \mathrm{m})$. The SNL could be no more than a layer of surface adsorbed $\mathrm{NO}_{2}$ or equivalent precursors on top of the water that is stabilized by a high adhesive force of attraction between the precursor molecule and water, which is less than the cohesive force of attraction between water molecules. The rapid and reversible development of surface layers of adsorbed $\mathrm{NO}_{2}$ have been noted in experimental studies on glass (George et al., 2005), a good model for a polar air/water interface. The SNL becomes saturated with nitrogen after exposure to a sufficient amount of $\mathrm{NO}_{2}$, and as time progresses during the night. If the $\mathrm{SNL}$ is completely saturated with $\mathrm{N}$ species $\left(\mathrm{NO}_{2}, \mathrm{~N}_{2} \mathrm{O}_{4}, \mathrm{ONONO}_{2}, \mathrm{NO}^{+} \mathrm{NO}_{3}^{-}, \mathrm{HONO}, \mathrm{HNO}_{3}\right)$, the subsequent $\mathrm{HONO}$ formation chemistry is independent of the concentration of $\mathrm{NO}_{2}$, i.e. $0^{\circ}$ order in $\mathrm{NO}_{2}$. If the surface

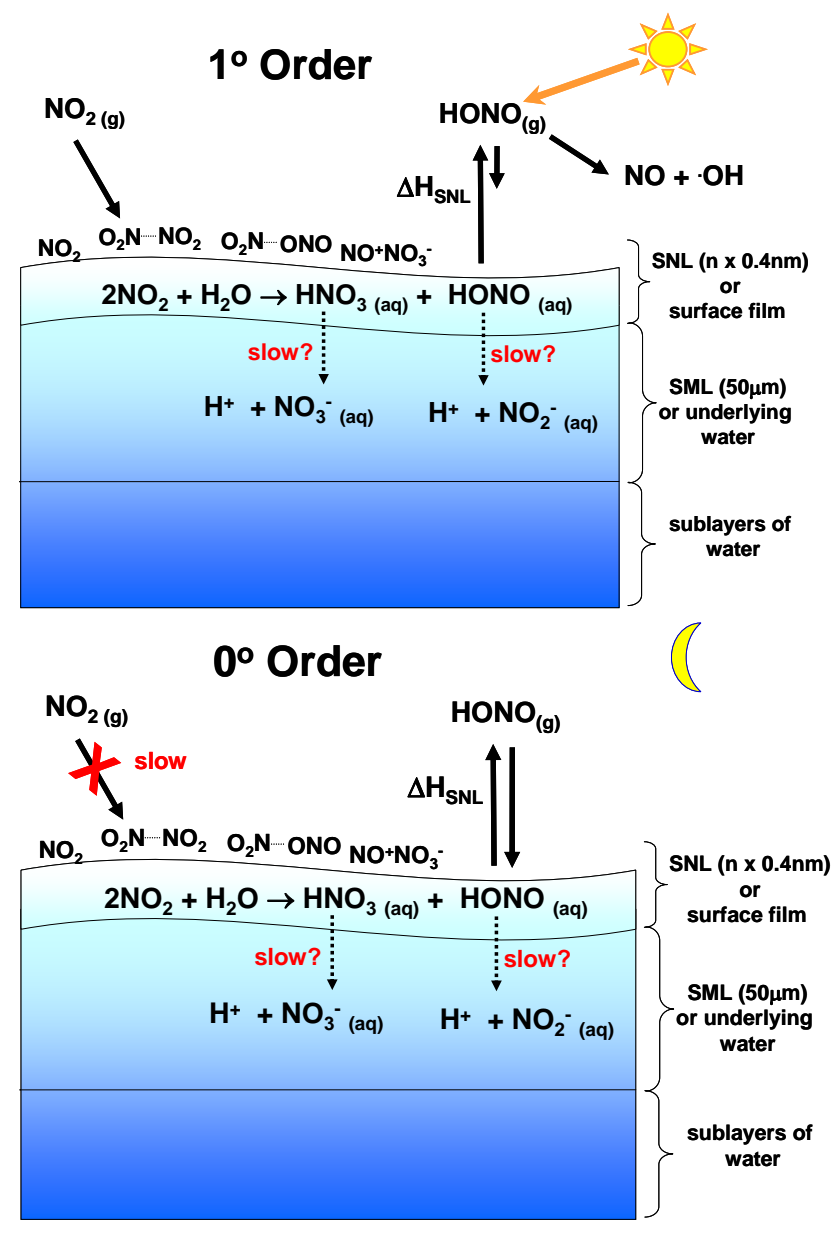

Fig. 9. Conceptual model of HONO formation mechanism on aqueous surfaces. The sea surface nanolayer (SNL) or surface film is from 1 to $n$ monolayers thick, and is highly acidic. Underlying layers include the sea surface microlayer (SML) in the case of the ocean or underlying water (dew, surface water, etc.) in the case of terrestrial surfaces, which would allow a medium for acid transport away from the SNL. (a) The formation of HONO is $1^{\circ}$ order in $\mathrm{NO}_{2}$, when irreversible loss of $\mathrm{HONO}$ (i.e. photolysis) from the SNL is faster than deposition of $\mathrm{NO}_{2}$ to the surface. (b) The formation of $\mathrm{HONO}$ is $0^{\circ}$ order in $\mathrm{NO}_{2}$, (i.e. a static system), when the $\mathrm{SNL}$ is saturated in $\mathrm{NO}_{2}$ precursors and irreversible losses of HONO from the SNL are negligible. $\mathrm{HONO}_{(\mathrm{g})}$ is dependent on the equilibrium dictated by Henry's Law for distribution of HONO between the SNL and gas phase.

layer is under saturated, then the system reverts to HONO formation with $1^{\circ}$ order kinetics in the extreme, limited by the deposition of $\mathrm{NO}_{2}$ to the surface. The high surface density of the layer would provide the medium for close contact of nitrogen pairs and surface reactions necessary to generate all the surface species present in the mechanism presented by Finlayson-Pitts (2003). We previously calculated the maximum density of $\mathrm{N}$ that could be present on the ocean surface, suggesting that at night, exposure of the ocean surface 
to several ppb of $\mathrm{NO}_{2}$ would be necessary to completely saturate the surface to some equilibrium state. The density of $\mathrm{N}$ required to establish an equilibrium system in the SNL is not certain, although we note that that the SNL would be very acidic due to the production of $\mathrm{HNO}_{3}$. While we have no proof of the N density in the SNL, the upper limit is approximately equivalent to the surface density of a monolayer of water, $8.6 \times 10^{18} \mathrm{~mol} \mathrm{~m}^{-2}$. Finlayson-Pitts (2003) provided evidence for the existence of $\mathrm{N}_{2} \mathrm{O}_{4}$ in surface films of laboratory surfaces, and demonstrated that its uptake on the surface is enhanced or stabilized by the presence of $\mathrm{HNO}_{3}$. We presume that this important precursor, $\mathrm{N}_{2} \mathrm{O}_{4}$, would be present in the SNL as well, possibly formed in the gas phase as suggested, but also potentially formed at high reaction rates in the high $\mathrm{N}$ density of the SNL monolayer. The existence of the SNL, saturated with precursors at night and partially saturated at sunset, could explain our fast approach to a PSS at sunset, compared to urban areas. In urban environments, a SNL usually does not exist at sunset, and would form after wetting of surfaces has happened, and after the water has adsorbed sufficient $\mathrm{NO}_{2}$.

In Fig. 9, we simplistically represent the detailed chemistry for HONO production by Reaction (R1), with mechanistic details that could be those offered by Finlayson-Pitts (2003) or Lammel (1999) or others. The final reaction by Finlayson Pitts (2003) would be:

$\mathrm{NO}^{+} \mathrm{NO}_{3}^{-}+\mathrm{H}_{2} \mathrm{O} \rightarrow \mathrm{HONO}_{\mathrm{SNL}}+\mathrm{HNO}_{3, \mathrm{SNL}}$

with equivalent products to those in Reactions (R1) and (R9). The HONO that is produced in the SNL would encounter a strongly acidic surface medium, supporting its reversible distribution to the atmosphere above:

$$
\mathrm{HONO}_{\mathrm{SNL}} \rightleftharpoons \mathrm{HONO}_{(\mathrm{g})} \quad \Delta H=\Delta H_{\mathrm{SNL}}(\mathrm{HONO})
$$

The enthalpy of Reaction (R11) accounts for all, or a significant portion of the temperature dependence we have observed during the PSS period. In Fig. 9, we included the diffusion of products, $\mathrm{HONO}$ and $\mathrm{HNO}_{3}$ into the underlying water as a slow process, although turbulence, wave breaking and bubble bursting in the ocean would all be mechanisms for transport of $\mathrm{N}(\mathrm{III})$ into sublayers and generation of $\mathrm{NO}_{2}^{-}$in a more alkaline medium (Reaction R3). We expect that $\mathrm{HONO}_{\mathrm{SNL}}$ is undissociated, as could be $\mathrm{HNO}_{3}$, depending on the surface density of nitrogen. The presence of sub layers of water allows diffusion of $\mathrm{HNO}_{3}, \mathrm{H}_{3} \mathrm{O}^{+}$ and $\mathrm{NO}_{3}^{-}$, away from the SNL. This transport would prevent the SNL from becoming too acidic, and could be an important distinguishing feature between the aqueous system, and HONO formation on "dry" or "humid" surface films. In the former, $\mathrm{NO}$ and $\mathrm{N}_{2} \mathrm{O}$ have been observed (FinlaysonPitts et al., 2003), likely due to the presence of $\mathrm{HNO}_{3}$ complexes in the concentrated film. The underlying layers of water in urban/suburban/rural aqueous systems would achieve the same goal. Thus the presence of the sublayers of water make Reaction (R11) truly reversible, since deposition of HONO to generate NO in a highly concentrated surface film could result in a loss of $\mathrm{N}$ and HONO from the PSS system. It is also worthy to note that there is a significant thermodynamic advantage to Reaction (R1) if the product is $\mathrm{HNO}_{3}$ (aq) $\left(\Delta H_{f}=-207.4 \mathrm{~kJ} \mathrm{~mol}^{-1}\right)$ compared to $\mathrm{HNO}_{3}(\mathrm{l})$ $\left(\Delta H_{f}=-174.1 \mathrm{~mol}^{-1}\right)$, the latter existing in extremely concentrated surface films in the limit of zero water.

A distinguishing feature between the two mechanisms in Fig. 9, is that when the mechanism operates under $1^{\circ}$ order $\mathrm{NO}_{2}$ kinetics, the reaction is pushed forward (left to right) by the irreversible loss of HONO from the SNL, likely dominated by photolysis of gaseous HONO. The surface layer is depleted at such times creating the conditions necessary for $1^{\circ}$ order kinetics. The system will continue to operate under $1^{\circ}$ order kinetics when photolysis stops at sunset for a short time, as HONO continues to be rapidly lost from the surface to establish a new steady state level of HONO, the PSS level. When the PSS level of HONO is reached, reversible deposition of HONO to the surface will dominate the loss of gaseous HONO, slowing down the depletion of nitrogen in the surface layer and created a saturated surface system again. Under these conditions, a quasi equilibrium system exists where uptake of $\mathrm{NO}_{2}$ at the surface will slow considerably, and the PSS of $\mathrm{HONO}$ is independent of $\mathrm{NO}_{2}$ concentration. The whole system would sit in static equilibrium, being driven forward only through the slow losses of $\mathrm{HNO}_{3}$ and HONO from the SNL (i.e. diffusion from the SNL to the SML). The formation of HONO under these conditions is zero order in $\mathrm{NO}_{2}$, represented by the equilibrium established between HONO partitioning between the SNL and the gas phase.

\subsection{Discussion and implications for atmospheric chemistry}

The aqueous model presented in Fig. 9 is representative for all aqueous systems, including the ocean, freshwater lakes, the surface of deliquesced aerosols and terrestrial surfaces coated with condensed water or precipitation. In the MBL, the aqueous surface is perpetual, day and night. In terrestrial locations and with absence of precipitation, condensed water appears later in the night as the RH increases. Condensed water on grass surfaces for example can be seen at $\mathrm{RH} \sim 80 \%$ (personal observation). The transition from a dry or humid HONO formation mechanism, to an aqueous PSS mechanism would be characterized by the time at which increasing HONO levels out to a period of $d[\mathrm{HONO}] / d t \approx 0$, perhaps with overshoot of the PSS level before return to the PSS level (Stutz et al., 2004). The overshoot could be attributed to the presence of a variety of surfaces that form condensed water over a range of relative humidities (Lammel, 1999). If the aqueous system is truly operational with a fully saturated SNL, then the PSS level of HONO, created by a 
thermodynamic equilibrium, should in principle be independent of $\mathrm{NO}_{2}$, relative humidity, and $S / V$ ratio, and could be easily predicted with knowledge of the temperature. The zero order dependence in $\mathrm{NO}_{2}$ during the PSS period makes previous literature difficult to interpret that have used $\mathrm{HONO} / \mathrm{NO}_{2}$ ratios at all times, implicitly implying $\mathrm{HONO}$ formation that is $1^{\circ}$ order in $\mathrm{NO}_{2}$. The evaporation of a terrestrial aqueous system after sunrise could also release significant amounts of nitrogen in many forms including $\mathrm{HONO}, \mathrm{NO}, \mathrm{NO}_{2}$ and $\mathrm{HNO}_{3}$, as observed previously for HONO (Zhou et al., 2002; Acker et al., 2004; He et al., 2006), that may be difficult to interpret. Thus storage of nitrogen in the SNL of aqueous water could be considerable.

The aqueous system would only operate where a suitable SNL could be established, requiring exposure of surface water to a certain amount of $\mathrm{NO}_{2}$ and/or HONO. This threshold level is difficult to predict without knowing the nitrogen density that would exist in the SNL, and will likely be related to the $S / V$ ratio of the environment. We have made arguments that the amount of $\mathrm{NO}_{2}$ to saturate a geometrically flat aqueous layer would have an upper limit of $\sim 3.4 \mathrm{ppb}$ for a $100 \mathrm{~m}$ boundary layer when the surface starts clean, as may happen after a precipitation event or rapid condensation on dry surfaces. An additional amount of $\mathrm{NO}_{2}$ equivalent to the PSS level of HONO would be also be required, typically $1 \mathrm{ppb}$. The data in central Birmingham (1-5 February 1993) (Harrison et al., 1996) are very interesting in this regard as they appear to show evidence on a nightly basis of $\mathrm{NO}_{2}$ depletions of 10-25 ppb, as HONO climbs, generating HONO PSS levels of 1-2 ppb. If an aqueous system were not operating, one would expect $\mathrm{NO}_{2}$ depletions of only $2 \times[\mathrm{HONO}]_{\mathrm{PSS}}$, based on Reaction (R1) stoichiometry. The $\mathrm{NO}_{2}$ depletions are much greater than $2 \times[\mathrm{HONO}]_{\mathrm{PSS}}$, and could be evidence of the depletion of $\mathrm{NO}_{2}$ through establishment of an urban SNL where a high $S / V$ ratio exists in the urban environment. Further analysis including transport, recent precipitation, nocturnal boundary layer height analysis would be needed to verify this.

In the remote marine boundary layer, we expect it probable that there is an insufficient amounts of $\mathrm{NO}_{2}$ for the establishment of a saturated SNL. We base this on the only other report of HONO measured in the MBL (Večeřa et al., 2008). In that report, as the ship travelled the Agean Sea, it experienced a range of $\mathrm{HONO}$ from below $50 \mathrm{ppt}$ to $2.7 \mathrm{ppb}$ as it encountering air masses with widely different $\mathrm{NO}_{2}$ levels. The HONO formation in a clean MBL could revert to a formation mechanism that is $2^{\circ}$ order in $\mathrm{NO}_{2}$, as the binary reactions of $\mathrm{NO}_{2}$ precursors on the surface of the monolayer could become the rate limiting step.

Another important implication of this work is the prediction that a SNL system could be operational both day and night in areas with high $\mathrm{NO}_{\mathrm{x}}$ emissions in proximity to oceans and freshwater lakes. As photolysis of HONO during the day would dominate, the SNL system would eventually begin to form $\mathrm{HONO}$ under $1^{\circ}$ kinetics, representing a signif- icant pump for the production of $\mathrm{OH}$ radicals, not just in the early morning, but as long as the system continues to operate, likely limited by the rate of uptake of $\mathrm{NO}_{2}$ to the surface. The following reactions outline a simplified daytime mechanism to illustrate the process, where the production mechanism in the SNL is again represented simply as Reaction (R1). The reversible return of $\mathrm{HONO}_{(\mathrm{g})}$ to the SNL (R11) has been removed presuming that photolysis of $\mathrm{HONO}_{(\mathrm{g})}$ is faster than the deposition loss rate of $\mathrm{HONO}_{(\mathrm{g})}$ to the ocean surface during the day. In reality, there will a competition.

$$
\begin{aligned}
& \mathrm{NO}_{2}(\mathrm{~g}) \rightarrow \mathrm{NO}_{2}(\mathrm{SNL}) \\
& 2 \mathrm{NO}_{2(\mathrm{SNL})}+\mathrm{H}_{2} \mathrm{O} \rightarrow \mathrm{HONO}_{(\mathrm{SNL})}+\mathrm{HNO}_{3(\mathrm{SNL})} \\
& \mathrm{HNO}_{3(\mathrm{SNL})} \rightarrow \mathrm{HNO}_{3(\mathrm{SML})} \\
& \mathrm{HONO}_{(\mathrm{SNL})} \rightarrow \mathrm{HONO}_{(\mathrm{g})} \\
& \mathrm{HONO}_{(\mathrm{g})}+h v \rightarrow \mathrm{NO}_{(\mathrm{g})}+\mathrm{OH}_{(\mathrm{g})} \\
& \mathrm{NO}_{(\mathrm{g})}+\mathrm{O}_{3} \rightarrow \mathrm{NO}_{2}(\mathrm{~g})+\mathrm{O}_{2}(\mathrm{~g})
\end{aligned}
$$

The net daytime reaction is obtained from addition of these reactions (2(R12)+R13-R18), where a sufficient amount of $\mathrm{O}_{3}$ to titrate the $\mathrm{NO}$ is assumed:

$\mathrm{NO}_{2(\mathrm{~g})}+\mathrm{O}_{3}+\mathrm{H}_{2} \mathrm{O}+h v \rightarrow \mathrm{HNO}_{3(\mathrm{SML})}+\mathrm{OH}_{(\mathrm{g})}+\mathrm{O}_{2}(\mathrm{~g})$

The net reaction predicts loss of odd oxygen $\left(\mathrm{O}_{3}+\mathrm{NO}_{2}\right)$ in the boundary layer to generate $\mathrm{HNO}_{3}$ in the SML and a quantitative amount of $\mathrm{OH}$. It should be possible to detect this mechanism if it exists by measuring a negative flux of odd oxygen from the surface (positive gradient, $\left.d\left[\mathrm{NO}_{2}+\mathrm{O}_{3}\right] / d z>0\right)$ and a positive flux of $\mathrm{OH}$ from the surface $(d[\mathrm{OH}] / d z<0)$. This mechanism would break down if odd oxygen is significantly depleted in the MBL.

\section{Conclusions}

We report measurements of nocturnal HONO in a polluted marine boundary layer, the first such measurements of their kind, and have performed a detailed analysis of this dataset to gain a better understanding of the formation and destruction mechanism of HONO in the atmosphere. The environment was unique because the surfaces are predominantly aqueous. The temporal behaviour of HONO over aqueous systems is unique, with nightly formation of pseudo steady states of HONO shortly after sunset, a balance between formation and deposition. While nocturnal PSSs of HONO have been observed in terrestrial polluted areas later at night, they were thought to be a balance between a HONO formation process on surfaces that is $1^{\circ}$ order in $\mathrm{NO}_{2}$, and a $1^{\circ}$ order deposition loss of $\mathrm{HONO}$ to the surface, possibly irreversible. We have found that over the ocean, the levels of HONO during the PSS period are largely independent of $\mathrm{NO}_{2}$, a clear signal of a $0^{\circ}$ order process. This suggests that a reservoir of HONO and/or nitrogen precursors must exist in the MBL and/or a reversible loss of HONO to the surface exists. Our calculations support a conclusion that this reservoir is likely on the 
surface of the ocean, close to saturation to support a $\mathrm{HONO}$ formation process that is $0^{\circ}$ order in $\mathrm{NO}_{2}$. With minor modifications to the mechanisms of others, we present a conceptual model for HONO formation in aqueous systems. The elements of the model include a pool of N(IV) species concentrated on the surface of the ocean in a few monolayers, $n$, that react to produce $\mathrm{HNO}_{3}(\mathrm{~N}(\mathrm{~V}))$ and $\mathrm{HONO}(\mathrm{N}(\mathrm{III}))$ in an acidic environment. We call this layer the sea surface nanolayer $\left(\mathrm{SNL}, t_{\mathrm{SNL}}=n \times 0.4 \mathrm{~nm}\right.$ ), in keeping with convention in chemical oceanography where research on the sea surface microlayer (SML) proceeds. The $\mathrm{HNO}_{3}$ is highly soluble and diffuses into the SML representing a slow loss of nitrogen from the SNL and a source to the SML. The HONO produced in the SNL escapes to the gas phase in a reversible process balanced by its deposition to the SNL. This reversible process represents a dynamic equilibrium dictated by Henrys Law. We observe a temperature dependence for this process that is consistent with an enthalpy for release of HONO from the surface with $\Delta H_{\mathrm{SNL}}=55.5 \pm 5.4 \mathrm{~kJ} \mathrm{~mol}^{-1}$, slightly larger than $\Delta H_{\mathrm{vap}}=40.7 \pm 1.2 \mathrm{~kJ} \mathrm{~mol}^{-1}$ for HONO partitioning from pure water. The extra $14.8 \pm 5.5 \mathrm{~kJ} \mathrm{~mol}^{-1}$ could represent an extra stabilization of HONO in the high nitrogen environment of the SNL matrix, or it could indicate an additional enthalpy of a related process occurring in the saturated SNL system.

There is evidence in our data that during the PSS state, the HONO formation mechanism may operate between $0^{\circ}$ and $1^{\circ}$ states, again indicative of a surface mechanism that could become saturated. The evidence for this comes from an increase in the $\mathrm{HONO} / \mathrm{NO}_{2}$ ratio from 0.13 to greater than 1 , as the night proceeds and with a lower limit seen at the start of the night of $\mathrm{HONO} / \mathrm{NO}_{2}=0.03$, similar to the maximum seen in other studies in dry environments. These numbers also suggest similarities between the HONO formation mechanisms on dry, humid and aqueous surfaces, with the maximum $\mathrm{HONO} / \mathrm{NO}_{2}$ ratios on dry surfaces of $\sim 0.03$, increasing, with RH on humid surfaces to $0.10-0.13$, and then increasing further in the case of aqueous surfaces as the night proceeds. This suggests a common surface mechanism to all surfaces, where the top monolayer of water may play an important support role for precursors, and increasing water available to the surface plays a role either because it is a limiting reagent or perhaps due to a thermodynamic advantage of the product state where $\mathrm{HNO}_{3}$ is dissolved.

Thus, the conceptual aqueous model we present should be representative of all aqueous surfaces including polluted coastal regions, freshwater lakes, deliquesced aerosol surfaces and other surfaces exposed to water. It is possible that the mechanism for HONO production can continue on aqueous surfaces under $1^{\circ}$ kinetics with respect to $\mathrm{NO}_{2}$ during the day, generating high amounts of the hydroxyl radical through HONO photolysis. We have demonstrated that the signal for such a mechanism operating during the day should be the loss of odd oxygen $\left(\mathrm{O}_{3}+\mathrm{NO}_{2}\right)$ from the boundary layer, close to the surface with an apparent positive flux of $\mathrm{OH}$ from the ocean which would be $1 / 2$ of the total negative flux of odd oxygen from the surface.

We further suggest, that the presence of a thin acid monolayer on top of the ocean or marine aerosols in polluted MBLs could provide the acid necessary to link the mechanism for generation of $\mathrm{Cl}_{2}$ in coastal environments at night, combined with the observations of Roberts (2008) that $\mathrm{ClNO}_{2}$ is a precursor to formation of $\mathrm{Cl}_{2}$, but only on acidified sea salt surfaces with $\mathrm{pH}<2.0$. The $\mathrm{Cl}_{2}$ could be formed on the surface of the aerosols or on the ocean surface following deposition of $\mathrm{ClNO}_{2}$ to the surface.

In future, there could be immediate benefit from reanalysis of past HONO data sets where temperature and other supporting meteorological data are available in urban areas. Especially missing from the literature is the reporting of supporting temperature and water vapor data. The verification of the existence of PSSs in urban areas would be in order, with a view to understanding negative fluxes of $\mathrm{NO}_{2}$ necessary to create the SNL, in terms of surface to volume ratios, the temporal extent of HONO production into daylight hours, and the consequences of an evaporation of the SNL at sunrise every day with release of stored nitrogen precursors. The temperature dependence of the HONO PSS should be verified in freshwater systems. On a molecular scale, more research is needed to determine the molecular density and the chemical nature of the SNL formed on aqueous systems. A better understanding of the aqueous mechanism would be obtained in future field studies if gradients and fluxes of $\mathrm{HONO}, \mathrm{NO}_{2}$ and $\mathrm{O}_{3}$ and other relevant species were measured both day and night in aqueous environments. The implications of the heterogeneous mechanism operating in polluted coastal and lakeside cities should be determined, with the help of modelers who would need to develop new algorithms to represent the aqueous mechanism in air quality models.

As a final note, we have not yet explored the implications of the acidic SNL on uptake of other gases on the ocean surface. It is likely that the deposition of anthropogenic $\mathrm{NO}_{2}$ and $\mathrm{HNO}_{3}$ contributes to ocean acidification on a local scale, but at the same time, it could have a negative feedback by slowing the uptake of other acidic gases, such as $\mathrm{CO}_{2}$, to the bulk water below. This could be the case if the $\mathrm{pH}$ at the surface of the ocean deviates significantly from normal alkaline conditions, where the ocean is normally a net sink for atmospheric $\mathrm{CO}_{2}$. The relationship between these opposing factors should be investigated, especially in light of the recently observed upwelling of acidified ocean currents along the continental shelf of Pacific North America, not far from where our study was conducted (Freely et al., 2008).

Acknowledgement. The authors acknowledge funding from the National Science and Engineering Research Council of Canada. We thank Joy McCourt and Daniel Majonis for assistance in experimental work, and lighthouse keepers Roy and Marie Barrows for their hospitality and generosity during our stay at Saturna Island.

Edited by: A. Hofzumahaus 


\section{References}

Acker, K., Wieprecht, W., Auel, R., Kalass, D., and Möller, D.: Evidence for heterogeneous formation of nitrous acid on cloud droplets, J. Aerosol Sci., 31(1), S352-S353, 2000.

Acker, K., Spindler, G., and Brüggemann, E.: Nitrous and nitric acid measurements during the INTERCOMP2000 campaign in Melpitz, Atmos. Environ., 38, 6497-6505, 2004.

Alicke, B., Platt, U., and Stutz, J.: Impact of nitrous acid photolysis on the total hydroxyl radical budget during the limitation of oxidant production/Pianura Padana Produzione di Ozono study in Milan, J. Geophys. Res., 107(D22), 8196, doi:10.1029/2000JD000075, 2002.

Alicke, B., Geyer, A., Hofzumahaus, A., Holland, F., Konrad, S., Pätz, H. W., Schäfer, J., Stutz, J., Volz-Thomas, A., and Platt, U.: $\mathrm{OH}$ formation by HONO photolysis during the BERLIOZ experiment, J. Geophys. Res., 108, 8247, doi:10.1029/2001JD000579, 2003.

Aubin, D. G. and Abbatt, J. P. D.: Interaction of $\mathrm{NO}_{2}$ with hydrocarbon soot: focus on HONO yield, surface modification, and mechanism, J. Phys. Chem. A, 111, 6263-6273, 2007.

Becker, K. H., Kleffmann, J., Kurtenbach, R., and Wiesen, P.: Solubility of nitrous acid (HONO) in sulfuric acid solutions, J. Phys. Chem., 100, 14984-14990, 1996.

Bongartz, A., Kames, J., Welter, F., and Schurath, U.: Near-UV absorption cross sections and trans/cis equilibrium of nitrous acid, J. Phys. Chem., 95, 1076-1082, 1991.

Bongartz, A., Kames, J., Schurath, U., George, Ch., Mirabel, Ph., and Ponche, J. L.: Experimental determination of HONO mass accommodation coefficients using two different techniques, J. Atmos. Chem., 18, 149-169, 1994.

Brown, S. S., Dibb, J. E., Stark, H., Aldener, M., Vozella, M., Whitlow, S., Williams, E. J., Lerner, B. M., Jakoubek, R., Middlebrook, A. M., DeGouw, J. A., Warneke, C., Goldan, P. D., Kuster, W. C., Angevine, W. M., Sueper, D. T., Quinn, P. K., Bates, T. S., Meagher, J., Fehsenfeld, F. C., and Ravishankara, A. R.: Nighttime removal of $\mathrm{NO}_{\mathrm{x}}$ in the summer marine boundary layer, Geophys. Res. Lett., 32, L07108, doi:10.1029/2004GL019412, 2004.

Chameides, W. L. and Stelson, A. W.: Aqueous-phase chemical processes in deliquescent seasalt aerosols, Ber. Bunsenges. Phys. Chem., 96, 461-470, 1992.

Cheung, J. L., Li, Y. Q., Boniface, J., Shi, Q., Davidovits, P., Worsnop, D. R., Jayne, J. T., and Kolb, C. E.: Heterogeneous interactions of $\mathrm{NO}_{2}$ with aqueous surfaces, J. Phys. Chem. A, 104, 2655-2662, 2000.

Dentener, F. J. and Crutzen, P. J.: Reaction of $\mathrm{N}_{2} \mathrm{O}_{5}$ on tropospheric aerosols: impact on the global distributions of $\mathrm{NO}_{\mathrm{x}}, \mathrm{O}_{3}$, and $\mathrm{OH}$, J. Geophys. Res., 98, 7149-7163, 1993.

Environment Canada, National Climate Data and Information Archive, available at: http://www.climate.weatheroffice.ec.gc. ca/welcome_e.html, 2008.

Finlayson-Pitts, B. J., Ezell, M. J., and Pitts Jr., J. N.: Formation of chemically active chlorine compounds by reactions of atmospheric $\mathrm{NaCl}$ particles with gaseous $\mathrm{N}_{2} \mathrm{O}_{5}$ and $\mathrm{ClONO}_{2}$, Nature, 337, 241-244, 1989.

Finlayson-Pitts, B. J., Wingen, L. M., Sumner, A. L., Syomin, D., and Ramazan, K. A.: The heterogeneous hydrolysis of $\mathrm{NO}_{2}$ in laboratory systems and in outdoor and indoor atmospheres: an integrated mechanism, Phys. Chem. Chem. Phys., 5, 223-242,
2003.

Freely, R. A., Sabine, C. L., Hernandez-Ayon, J. M., and Ianson Debby, H. B.: Evidence for upwelling of corrosive "acidified" water onto the continental shelf, Science, 320, 1490-1492, 2008.

George, C., Strekowski, R. S., Kleffmann, J., Stemmler, K. and Ammann, M.: Photoenhanced uptake of gaseous $\mathrm{NO}_{2}$ on solid organic compounds: A photochemical source of HONO, Faraday Discuss., 130, 195-210, 2005.

Grasshoff, K.: Hydrochemistry of landlocked basins and fjords, in: Chemical Oceanography, Vol. 2, edited by: Riley, J. P. and Skirrow, G., Academic Press, New York, USA, 456-598, 1975.

Hardy, J. T.: The sea surface microlayer: biology, chemistry and anthropogenic enrichment, Progress Oceanogr., 11, 307-328, 1982.

Harris, G. W., Carter, W. P. L., Winer, A. M., Abbas, A. A., Pitts Jr., J. N. Platt, U., and Perner, D.: Observations of nitrous acid in the Los Angeles atmosphere and implications for predictions of ozone-precursor relationships, Environ. Sci. Technol., 16, 414419, 1982.

Harrison, R. M. and Kitto, A. M. N.: Evidence for a surface source of atmospheric nitrous acid, Atmos. Environ., 28, 1089-1094, 1994.

Harrison, R. M., Peak, J. D., and Collins, G.: Tropospheric cycle of nitrous acid, J. Geophys. Res., 101, 14429-14439, 1996.

He, Y., Zhou, X., Hou, J., Gao, H., Bertman, S.: Importance of dew in controlling the air-surface exchange of HONO in rural forested environments, Geophys. Res. Lett., 33, L02813, doi:10.1029/2005GL024348, 2006.

Hermans, C., Vandaele, A. C., Carleer, M., Fally, S., Colin, R., Jenouvrier, A., Coquart, B., and Mérienne, M.-F.: Absorption cross-sections of atmospheric constituents: $\mathrm{NO}_{2}, \mathrm{O}_{2}$, and $\mathrm{H}_{2} \mathrm{O}$, Environ. Sci. Poll. Res., 6, 151-158, 1999.

Jenkin, M. E., Cox, R. A., and Williams, D. J.: Laboratory studies of the kinetics of formation of nitrous acid from the thermal reaction of nitrogen dioxide and water vapour, Atmos. Environ., 22, 487498, 1988.

Junkermann, W. and Ibusuki, T.: FTIR spectroscopic measurements of surface bond products of nitrogen oxides on aerosol surfaces - implications for heterogeneous $\mathrm{HNO}_{2}$ production, Atmos. Environ., 26A, 3099-3103, 1992.

Kitto, A. M. N. and Harrison, R. M.: Nitrous and nitric acid measurements at sites in South-East England, Atmos. Environ., 26A, 235-241, 1992.

Kleffmann, J., Kurtenbach, R., Lorzer, J. C., Wiesen, P., Kalthoff, N., Vogel, B. and Vogel, H.: Measured and simulated vertical profiles of nitrous acid, part I: Field measurements, Atmos. Environ., 37, 2949-2955, 2003.

Kraus, S. G.: DOASIS: a framework design for DOAS, Thesis, Universität Mannheim, Germany, 2006.

Kurtenbach, R., Becker, K. H., Gomes, J. A. G., Kleffmann, J., Lörzer, J. C., Spittler, M., Wiesen, P., Ackermann, R., Geyer, A., and Platt, U.: Investigations of emissions and heterogeneous formation of HONO in a road traffic tunnel, Atmos. Environ., 35, 3385-3394, 2001.

Lammel, G.: Formation of nitrous acid: parameterisation and comparison with observations. Rep. 286, Max-Planck-Institut für Meteorologie, 1999.

Lammel, G. and Cape, J. N.: Nitrous acid and nitrite in the atmosphere, Chem. Soc. Rev., 25, 361-369, 1996.

McLaren, R., Wojtal, P., Majonis, D., McCourt, J., Halla, J. D., and 
Brook, J.: $\mathrm{NO}_{3}$ radical measurements in a polluted marine environment: links to ozone formation, Atmos. Chem. Phys., 10, 4187-4206, doi:10.5194/acp-10-4187-2010, 2010.

Mertes, S. and Wahner, A.: Uptake of nitrogen dioxide and nitrous acid on aqueous surfaces, J. Phys. Chem., 99, 14000-14006, 1995.

Osthoff, H. D., Roberts, J. M., Ravishankara, A. R., Williams, E. J., Lerner, B. M., Sommariva, R., Bates, T. S., Coffman, D., Quinn, P. K., Dibb, J. E., Stark, H., Burkholder, J. B., Talukdar, R. K., Meagher, J., Fehsenfeld, F. C., and Brown, S. S.: High levels of nitryl chloride in the polluted subtropical marine boundary layer, Nature Geosci., 1, 324-328, doi:10.1038/ngeo177, 2008.

Park, J.-Y. and Lee, Y.-N.: Solubility and decomposition kinetics of nitrous acid in aqueous solution, J. Phys. Chem., 92, 6294-6302, 1988.

Platt, U., Perner, D., Harris, G. W., Winer, A. M., and Pitts Jr., J. N.: Observations of nitrous acid in an urban atmosphere by differential optical absorption, Nature, 285, 312-314, 1980.

Ponche, J. L., George, Ch., and Mirabel, Ph.: Mass transfer at the air/water interface: mass accomodation coefficients of $\mathrm{SO}_{2}$, $\mathrm{HNO}_{3}, \mathrm{NO}_{2}$ and $\mathrm{NH}_{3}$, J. Atmos. Chem., 16, 1-21, 1993.

Roberts, J. M., Osthoff, H. D., Brown, S. S., and Ravishankara, A. R.: $\mathrm{N}_{2} \mathrm{O}_{5}$ oxidizes chloride to $\mathrm{Cl}_{2}$ in acidic atmospheric aerosol, Science, 321, 1059-1100, 2008.

Stutz, J., Alicke, B., and Neftel, A.: Nitrous acid formation in the urban atmosphere: gradient measurements of $\mathrm{NO}_{2}$ and HONO over grass in Milan, Italy, J. Geophys. Res., 107, 8192, doi:10.1029/2001JD00390, 2002.

Stutz, J., Alicke, B., Ackermann, R., Geyer, A., Wang, S., White, A. B., Williams, E. J., Spicer, C. W., and Fast, J. D.: Relative humidity dependence of HONO chemistry in urban areas, J. Geophys. Res., 109, D03307, doi:10.1029/2003JD004135, 2004.

Stutz, J. and Platt, U.: Improving long-path differential optical absorption spectroscopy with a quartz-fiber mode mixer, Appl. Opt., 36, 1105-1115, 1997.

Tang, I. N., Tridico, A. C., and Fung, K. H.: Thermodynamic and optical properties of sea salt aerosols, J. Geophys. Res., 102, 23269-23275, 1997.

Vandaele, A. C., Simon, P. C., Guilmot, J. M., Carleer, M., and Colin, R.: $\mathrm{SO}_{2}$ absorption cross section measurement in the UV using a Fourier transform spectrometer, J. Geophys. Res., 99(D12), 25599-25605, 1994.
Vandaele, A. C., Hermans, C., Simon, P. C., Carleer, M., Colin, R., Fally, S., Mérienne, M.-F., Jenouvrier, A., and Coquart, B.: Measurements of the $\mathrm{NO}_{2}$ absorption cross-section from $42000 \mathrm{~cm}^{-1}$ to $10000 \mathrm{~cm}^{-1}(238-1000 \mathrm{~nm})$ at $220 \mathrm{~K}$ and 294 K, J. Quant. Spectrosc. Rad., 59, 171-184, 1998.

Večeřa, Z., Mikuska, P., Smolik, J., Eleftheriadis, K., Bryant, C., Colbeck, I., and Lazaridis, M.: Shipboard measurements of nitrogen dioxide, nitrous acid, nitric acid and ozone in the Eastern Mediterranean Sea, Water Air Soil Pollut. Focus, 8, 117-125, 2008.

Wang, S., Ackermann, R., and Stutz, J.: Vertical profiles of $\mathrm{O}_{3}$ and $\mathrm{NO}_{x}$ chemistry in the polluted nocturnal boundary layer in Phoenix, AZ: I. Field observations by long-path DOAS, Atmos. Chem. Phys., 6, 2671-2693, doi:10.5194/acp-6-2671-2006, 2006.

Yu, Y., Galle, B., Panday, A., Hodson, E., Prinn, R., and Wang, S.: Observations of high rates of $\mathrm{NO}_{2}-\mathrm{HONO}$ conversion in the nocturnal atmospheric boundary layer in Kathmandu, Nepal, Atmos. Chem. Phys., 9, 6401-6415, doi:10.5194/acp-9-6401-2009, 2009.

Zafiriou, O. C. and True, M. B.: Nitrite photolysis in seawater by sunlight, Marine Chem., 8, 9-32, 1979.

Zhang, Z., Liu, L., Wu, Z., Li, J., and Ding, H.: Physicochemical studies of the sea surface microlayer: I. Thickness of the sea surface microlayer and its experimental determination, J. Coll. Interf. Sci., 204, 294-299, 1998.

Zhang, Z. B., Pan, M. X., Wang, Z. D., Zhao, W., Huang, H. H., Wei, G. F., Gao, H. L., Peng, Y. H., Zhu, Z. H., and Li, L.: Biological and chemical studies of sea surface microlayer (SML) in Daya Bay, China, Chin. J. Oceanol. Limnol., 19, 272-281, 2001.

Zhang, Z. B., Liu, C., and Liu, L.: Physicochemical studies of the sea-surface microlayer, Front. Chem. China, 1, 1-14, doi:10.1007/s11458-005-0003-8, 2006.

Zhou, X., Civerolo, K., Dai, H., Huang, G., Schwab, J. J., and Demerjian, K. L., Summertime nitrous acid chemistry in the atmospheric boundary layer at a rural site in New York State, J. Geophys. Res., 107(D21), 4590, doi:10.1029/2001JD001539, 2002. 